\title{
LA FORMACIÓN DE ESTRATEGIAS DELIBERADAS Y EMERGENTES: UNA PROPUESTA A PARTIR DE DEFINICIONES BÁSICAS DE UNA METODOLOGÍA DE SISTEMAS SUAVES*
}

\author{
IVÁN ALONSO MONTOYA RESTREPO*** \& LUZ ALEXANDRA MONTOYA RESTREPO***** \\ UNIVERSIDAD NACIONAL DE COLOMBIA
}

Recibido/ Received/ Recebido: 20/03/2012 - Aceptado/ Accepted / Aprovado: 11/06/2013

\begin{abstract}
Resumen
La propuesta teórica que se presenta, se relaciona con la formación de la estrategia desde una perspectiva evolutiva y con conexiones entre estrategias deliberadas y emergentes, gracias al empleo de definiciones básicas o raíces, empleando la metodología de sistemas suaves SSM propuesta por Checkland \& Scholes (1994). Para ello se propone la interacción de entes "autónomos" y semióticos (agentes, organizaciones y entorno) en los sistemas real y representacional de interacciones. Estas nociones permiten la elaboración de los conceptos de decisión, actuación e intencionalidad. Se reelaboran las nociones de estrategia deliberada y emergente y se detalla un ciclo de operación entre tales tipos de estrategia.
\end{abstract}

Palabras clave: Estrategias deliberadas, Estrategias emergentes, Metodología de sistemas suaves, Decisión.

\section{DEVELOPMENT OF DELIBERATE AND EMERGING STRATEGIES: A PROPOSAL BASED ON BASIC DEFINITIONS FROM A SOFT SYSTEMS METHODOLOGY}

\begin{abstract}
This theoretical proposal, is related to the strategy development from an evolutional perspective and connections between deliberate and emerging strategies, using basic definitions and soft systems methodology (SSM) proposed by Checkland \& Scholes (1994). In order to achieve this, an interaction among "autonomous" and semiotic (agents, organizations and surroundings) entities in real and representative interaction systems is proposed. These notions allow establishing decision, performance and intentionality concepts. Deliberate and emerging strategy notions are restated and an operation cycle among strategy types is detailed.
\end{abstract}

Keywords: Deliberate Strategies, Emerging Strategies, Soft system methodology, Decision.

Documento resultado del proyecto institucional "Formación de la estrategia y prospectiva", que los autores adelantan en la Facultad de Minas de la Universidad Nacional de Colombia (Medellín).

*** Administrador de empresas, Magister en administración de empresas y doctor en Ciencias económicas de la Universidad Nacional de Colombia (Bogotá), Profesor Asociado, Facultad de Minas, Universidad Nacional de Colombia. Correo electrónico: iamontoyar@ unal.edu.co

**:* Administradora de empresas, Magister en administración de empresas y doctora en Ciencias económicas de la Universidad Nacional de Colombia (Bogotá), Profesora Asociada, Facultad de Minas, Coordinadora nacional del Concurso docente, Universidad Nacional de Colombia. Correo electrónico: lamontoyar@unal.edu.co 


\title{
A FORMAÇÃO DE ESTRATÉGIAS DELIBERADAS E EMERGENTES: UMA PROPOSTA A PARTIR DE DEFINIÇÕES BÁSICAS DE UMA METODOLOGIA DE SISTEMAS SUAVES
}

\section{Resumo}

\begin{abstract}
A proposta teórica que se apresenta, relaciona-se com a formação da estratégia desde uma perspectiva evolutiva e com conexões entre estratégias deliberadas e emergentes, graças ao emprego de definições básicas ou raízes, empregando a metodologia de sistemas suaves SSM proposta por Checkland \& Scholes (1994). Para isso se propõe a interação de entes "autônomos" e semióticos (agentes, organizações e meio) nos sistemas real e representacional de interações. Estas noções permitem a elaboração dos conceitos de decisão, atuação e intencionalidade. Reelaboram-se as noções de estratégia deliberada e emergente e se detalha um ciclo de operação entre tais tipos de estratégia. Palavras chave: Estratégias deliberadas, Estratégias emergentes, Metodologia de sistemas suaves, Decisão.
\end{abstract}

Montoya, I. \& Montoya, L. (2013) Propuesta sobre la formación de estrategias deliberadas y emergentes, mediante definiciones básicas de una metodología de sistemas suaves. En: Revista de la Facultad de Ciencias Económicas de la Universidad Militar Nueva Granada. rev.fac.cienc.econ, XXI (2)

JEL: M10, M14, M19.

\section{Introducción}

La estrategia es generalmente aceptada como un patrón de pensamiento y acción, la cual suele quedar atrapada en un proceso de formación cuya racionalidad se ha transformado en instrumental, y en muchos programas de investigación se encuentra como un producto normativo, sin mucha posibilidad de reconocerse dentro de procesos evolutivos (Montoya, 2010).

La relevancia de la estrategia en la comprensión de procesos evolutivos se propone como auténtica, pues la misma se configura como orientadora de la acción de entes en distintos campos económicos y sociales. Las acciones emprendidas bajo la declaración que hace un ente de su percepción del mundo y la construcción de respuestas típicas a problemas genéricos, no sólo contribuyen a atenuar la comple- jidad en los procesos históricos del desenvolvimiento económico de las firmas, sino que contribuyen con las rutinas, capacidades dinámicas y otros dispositivos de retención, a establecer las trayectorias de su desarrollo.

La propuesta teórica se relaciona con la formación de la estrategia desde una perspectiva evolutiva y con las conexiones entre estrategias deliberadas y emergentes, desde una revisión de sus concepciones. Para su desarrollo se propone la interacción de entes, los cuales se definen como agentes, organizaciones y entorno, y se admite la posibilidad de agregación de agentes.

Los entes van a configurarse como sistemas abiertos y "agentes autónomos" en la definición de Kauffman $(2003)^{1}$, entendidos como sistemas auto-reproductores, en capacidad de desarrollar al menos un ciclo de

\footnotetext{
"Para Kauffman, el agente autónomo ha de ser un sistema termodinámico abierto impulsado por fuentes externas de materia y energía que mantenga al sistema fuera del equilibrio, a la manera del demonio de Maxwell. Kauffman sugiere que estos agentes enlazan procesos espontáneos y no espontáneos mediante complejas redes de interacciones que dan por resultado la reproducción y los persistentes ciclos de trabajo con los que actúan sobre el mundo. Al concluir dicho ciclo, el sistema está listo para iniciarlo de nuevo. Se alcanza una organización repetitiva del proceso (Kauffman, 2003). Son agentes autónomos los que acoplan ciclos de trabajo que constituyen una forma totalmente plausible de redes fuera del equilibrio" (Montoya, 2010, 81).
} 
trabajo termodinámico. Esta concepción involucra la idea que el ciclo sirve para elaborar condicionantes a la liberación de energía, lo cual se constituye, en un nuevo trabajo. Así, el trabajo que realiza el ente $\mathrm{de}$ acuerdo a su finalidad produce restricciones, $\mathrm{y}$ esas mismas restricciones se requieren para obtener trabajo. Los entes se relacionan con un entorno que también va a asemejarse a la definición de un ente, y exhibirán un comportamiento evolucionista que se establece como el proceso de cambio (de un ente), en las cuales la estructuración definitoria particular de cada entidad aparece como modificación de la anterior, constituyéndose de esta manera en su antecedente secuencial e histórico (en esta propuesta, con enfoque semiótico y pragmatista basado en las nociones peirceanas de primeridad, segundidad y terceridad).

Estos entes operando en un sistema económico, mostrarán las nociones peirceanas a través de los mecanismos de acumulación del aprendizaje y retención (terceridad), los procesos de posibilidad de variedad (primeridad) y los mecanismos de selección (segundidad) ${ }^{2}$.

El entorno va a formarse a la manera de un ente. Esta simplificación facilita que las interacciones enteentorno resulten en realidad como modelaciones entre ente - ente. Por otra parte, se aprecia un diseño holográfico entre suponer a agentes individuales, organizaciones y entornos como sistemas con características de descripción similares. De esta manera, la idea de sistema abierto como ente del tipo agente, organización y entorno, y la jerarquía sistémica que generan, es uno de los bloques de construcción de la propuesta, retomando la idea de modelación con bloques de Holland (2004).

El problema de la estrategia desde una perspectiva evolutiva, se presenta en un escenario en el cual in-

2 "Para Aldrich et al. (2008), la evolución de instituciones sociales involucra imitación, planeación y otros mecanismos muy diversos a los detallados en biología (Aldrich et al., 2008; Aldrich \& Ruef, 2006), mientras que la idea de retención, puede expresarse en evolución social mediante las nociones de replicación de hábitos, reglas y rutinas, y otras soluciones a problemas de adaptación. (Vanberg, 1994 citado en Aldrich et al., 2008). El primer mecanismo, de selección, se asocia al proceso de competencia entre las entidades de la población. Es por esto que resulta de relevancia esencial en el proceso de selección los criterios sobre los cuales el sistema económico selecciona a los supervivientes. Un criterio general corresponde al nivel de beneficios realizados por las firmas individuales, de forma que la aptitud o "fitness" de una firma puede ser en principio determinada sobre criterios diferentes e incluso conflictivos entre sí. La fitness económica, como medida de la tendencia diferencial de las firmas competidoras con respecto al crecimiento de las mismas, depende del efecto conjunto de las consecuencias del ambiente y de las posibilidades internas del negocio (Bleda, 2001). Finalmente, las firmas realizan un proceso de mutación que no necesariamente es ciego como sucede en Biología, al parecer de orientación "estratégica", de forma que pueden confrontar la misma información y tomar decisiones variadas, según su proceso de interpretación, el cual depende del desarrollo previo sobre el cual el conocimiento fue adquirido. La dependencia de sendero (path dependency) en el proceso de adquisición de conocimiento depende de la propia historia de la firma, de los aprendizajes culturales corporativos y de la experiencia adquirida (Teece, Pisano \& Shuen, 1997). Eisenhardt \& Martin (2000) sugieren que las diferencias en el rendimiento de las organizaciones se atribuyen a los diferentes caminos que las empresas han desarrollado en el curso de la construcción de sus capacidades, así como el tiempo invertido, por encima de las similitudes en sí mismas. El segundo mecanismo, de generación de variedad conduce a comprender cambios variacionales y transformacionales; los cambios variacionales son producidos por la composición de una población y surgen como el resultado de procesos de selección. Los cambios transformacionales se refieren a cualquier cambio que toma lugar en las características de las entidades individuales, representando la generación de variedad en el comportamiento entre la población. (Hodgson, 1994; Metcalfe, 1997; Bleda, 2001). Aunque es el cambio variacional el que tradicionalmente ha sido considerado como evolucionario, el cambio transformacional posee una elevada relevancia en las explicaciones evolucionarias toda vez que la generación de variedad en los niveles individuales constituyen un requisito necesario para que la evolución ocurra en el tiempo. En cuanto al tercer mecanismo, según Nelson \& Winter (1982), las rutinas juegan el rol que los genes realizan en la evolución biológica, y operan como mecanismos de almacenamiento de información o hábitos de pensamiento individuales o colectivos. En general las rutinas pueden ser definidas como patrones predecibles de un comportamiento más o menos coordinado, desarrollados por entidades del sistema económico para favorecer su operación continua en su propio ambiente, de forma que las entidades pueden vérselas con situaciones complejas y permiten reducir la demanda cognitiva de las mismas, favoreciendo su proceso de adaptación. El conocimiento acumulado cambia en el tiempo en tanto las experiencias son seleccionadas y retenidas, reproducidas en los procesos de creación o préstamo del crecimiento, favoreciendo que las rutinas preserven la estabilidad y confieran al sistema un elemento de inercia que previene a las entidades para que no reaccionen instantáneamente a las presiones de selección (Nelson \& Winter, 1982)" (Montoya, 2010, 63-64). 
dividuos hacen parte de organizaciones, y las organizaciones configuran un entorno. Se emplean como propiedades y mecanismos las siguientes, que provienen de la modelación en sistemas:

- La agregación, como una manera uniforme y reutilizable para simplificar en la representación de sistemas. Este mecanismo suele acompañarse de la identificación de simetrías a través de etiquetas que contribuyen en la formación de agregados.

- La representación de interacciones entre eventos de manera lineal y no lineal.

- La posibilidad de flujos. Los flujos son patrones que reflejan los cambios provocados por el proceso de adaptación a medida que pasa el tiempo y se acumulan experiencias.

- El uso de modelos internos para la anticipación y la predicción. De acuerdo con Holland (2004), la maniobra básica para construir modelos internos inicia con la agregación y la ponderación de los patrones seleccionados. El agente, debe distinguir patrones del flujo de información que recibe, y después debe convertir estos patrones en cambios en su estructura interna. Posteriormente, los cambios en la estructura van a volverse un modelo interno que le debe permitir anticiparse a consecuencias que se generan cuando el mismo patrón u otro similar vuelve a ser encontrado.

- La repetición de situaciones modeladas y su empleo en la modelación de otras, configura el empleo de bloques de construcción.

En la sección siguiente se presentan la pregunta, hipótesis y objetivos que originan la propuesta teórica.

\section{Pregunta de investigación y objetivos de la investigación}

La pregunta que orientó el proceso de investigación fue la de reflexionar sobre cómo se forma la estrategia desde una perspectiva evolutiva. El objetivo fue el de contribuir en explicar la formación de las estrategias deliberadas y emergentes como un proceso cíclico. Como objetivos específicos se tuvieron los siguientes:

- Explicar la formación de estrategias deliberadas, y sus alcances en relación con el aprendizaje de organizaciones, mediante un mecanismo evolutivo de selección,

- Explicar la formación de estrategias emergentes, mediante un mecanismo evolutivo termodinámico,

- Explicar una vinculación cíclica entre estrategias deliberadas y emergentes.

El presente artículo tiene como propósito mostrar los aspectos centrales de la reconstrucción del concepto de estrategia mediante la revisión de las concepciones clave en el proceso de formación de la misma, mediante el empleo de la metodología de sistemas suaves.

Por su parte, la metodología de Sistemas Suaves, propuesta por Peter Checkland, es un marco de intervención o interacción mediante el cual el observador identifica sistemas con propósito definido a partir de la observación de "mundos" complejos. Este observador se encarga de identificar diferentes formas de sistemas de actividad humana en diversas clases de ambientes o entornos y, a partir del ejercicio de delimitación que hace, con un propósito previamente definido, busca la definición básica o esencial del sistema identificado y la elaboración de modelos enriquecidos del mismo para compararlos con la realidad y proponer acciones deseables en cuanto al alcance de transformación que se le propone al sistema sobre el mundo real (Checkland \& Scholes, 1994). Esta metodología suele desarrollar como pasos la identificación de un problema o situación social u organizacional en el cual se espera reflexionar sobre la actividad humana con propósito definido; la expresión de la situación mediante diagramas enriquecidos; la elaboración de definiciones básicas o raíces; la elaboración de modelos conceptuales; la compraración de los modelos con el mundo real; la determinación de las acciones deseables y factibles que conduzcan a la acción para mejorar la situación problemática (Checkland \& Scholes, 1994). 


\section{Los entes del sistema}

\subsection{La concepción de agente}

Se asume que un agente es un sistema cognitivo habilitado para la toma de decisiones, que construye representaciones, valoraciones y perspectivas de su entorno, cuya racionalidad resulta limitada, y su posibilidad de aprendizaje depende en tanto ente, de su experiencia pasada y de su expectativa del mundo, lo que resulta en que un agente se emplea a sí mismo para mejorar su posibilidad de tomar decisiones. Esta habilitación corresponde a la búsqueda de la mejor acomodación estable en un "nicho-real" en el entorno, en el que pueda desarrollar ventajas termodinámicas. El agente dispone de un dispositivo ontológico - epistemológico que proviene de su posibilidad de interactuar con otros agentes y consigo mismo (en donde concurren visiones del mundo)con quienes puede obrar como un observador externo o interno-, y de sus condicionantes dados y generados. Las capacidades (e incluso la cognición sobre el empleo de recursos) propias del agente y el desarrollo de su particular proceso de aprendizaje, le generan una trayectoria, que habilita, potencia y limita la posibilidad de obtener, registrar y comprimir información y generar conocimiento aplicable para su propia viabilidad.

\subsection{Elementos de la definición esencial de agen- te mediante una definición básica ${ }^{3}$}

- Usuario: Otros agentes y él mismo.

- Actores: El agente interactúa consigo mismo, con otros agentes, con una organización en la que está inmerso como un agente más complejo, con otras organizaciones y con el entorno.

- Transformación: El agente procura acomodarse y posibilitar la estabilidad de su acomodación, en un "nicho real" que lo haga viable y en donde tenga eficiencia termodinámica, mediante la generación de un ciclo de trabajo termodinámico afortunado en un nicho real en el cual se pueda acomodar.

- Visión del mundo: Para la concepción de un agente se acoge una visión naturalista. Se habilita al agente para buscar su viabilidad con un dispositivo ontológico - epistemológico, en tanto puede interactuar consigo mismo y con otros agentes.

- $\quad$ Propietario: Él mismo.

- Entorno: La jerarquía sistémica de entes: agente, organización, entorno.

\subsection{Comentarios a la definición de agente}

En tanto sistema cognitivo se acogen ideas de una gran variedad de autores tales como Kauffman (2003), Hodgson (1994), Lewin \& Volberda (1999) y Chakravarthy \& White (2002) y se expresa esta definición a la manera de Hernández (2008).

La habilitación para la toma de decisiones acoge principalmente las ideas de la escuela de Carnegie Mellon y los aportes de Simon (1945), March \& Simon (1958), Cyert \& March (1963), quienes mencionan al agente como uno de racionalidad limitada y se critica sutilmente a Holland (2004) para quien la decisión puede modelarse como una ampliación de las condiciones de intercambio, mientras que en la presente definición se le da finalidad en términos de lo sugerido por Kauffman (2003) en cuanto a la robustez que da al ente para su viabilidad, la posibilidad de "encontrar" un nicho real en el cual desarrolla el ente un ciclo de trabajo con ventaja termodinámica.

Se amplía también aquí la posibilidad del agente para interactuar consigo mismo, cosa que en Holland sólo sucede cuando convierte recursos de su reserva en elementos para las condiciones de ataque, defensa,

3 Las definiciones básicas o raíces se construyen a partir de lo indicado en Checkland \& Scholes (1994) en la metodología de sistemas suaves, suelen requerir la identificación de los usuarios o beneficiarios del sistema, los actores relacionados, la visión del mundo implícita en la definición básica del sistema y el propósito de transformación de la realidad que el sistema procura en términos de la manera como es definido, su entorno y sus responsables o "propietarios". 
intercambio, etc., pero la interacción consigo mismo contribuirá a esclarecer el papel de la decisión, en su viabilidad. También se le posibilita a la noción de bloques de construcción enmarcarse dentro de una visión del mundo centrada en creencias, al sugerir que el agente dispone de un componente ontológico - epistemológico.

En la concepción peirceana de análisis fenomenológico, pueden estas manifestaciones descomponerse en tres categorías: la primeridad (lo espontáneo), la segundidad (lo determinado) y la terceridad (la representación propiamente dicha del fenómeno, lo que se desarrolla) (Peirce, 1965; Andrade, 2003). En términos de una propuesta de agente, la primeridad corresponde a la posibilidad de este ente de alojarse en un nicho real en tanto sistema autónomo en búsqueda de viabilidad. La segundidad corresponde a su estructura dada o actual de capacidades y aprendizaje (en tanto usos y combinaciones de recursos en sentido amplio, y elaboración de prácticas de conocimiento), y la terceridad a su posibilidad como agente interpretante y cognitivo, de la que derivará su realidad futura y su exhibición de poder (en tanto éste último es inseparable del conocimiento). La posibilidad de alojarse en un nicho real, está vinculada con la de potencialidad, la cual está asociada a la interpretación que da el ente al mundo real, fruto de su colección de experiencia, recogida en la terceridad como agente interpretante, y que hace que su percepción del mundo real se enuncie en términos de su discernimiento, lo que se expone como un proceso de proyección.

Se acoge la idea de Gindis (2007) sobre la ontología de los grupos y se le atribuye al agente la posibilidad de una propia ontología (sobre las suposiciones básicas que hace sobre la realidad) y epistemología (que le permite pensar y recrear críticamente las prácticas del conocimiento en el aprendizaje y cuya elección determina la forma de la producción e interpretación de las teorías sobre el mundo, siguiendo a Guyot, 2005). Esta última condición hace del agente uno praxístico -en tanto su posibilidad de elección de prácticas de conocimiento- y pragmático, debido a que su posibilidad como agente interpretante y cognitivo se enmarca en el constructo que el pensamiento tiene que ver con la creencia, y que la creencia tiene que ver con el hábito, a la luz de la existencia de posibilidades reales de viabilidad.

En la definición de lo indisincrático de su proceso de aprendizaje, se retoman varios autores, entre ellos a Teece $(1994)$ y Hodgson (2004).

\subsection{La concepción de organización}

La organización será un agregado de agentes, con una estructura interna donde compiten agentes por nichos reales y en donde se origina una personalidad característica del agregado, con una ontología propia. Así, se asume que una organización es un sistema cognitivo habilitado para la toma de decisiones, cuya racionalidad resulta limitada, y su posibilidad de aprendizaje depende en tanto ente, de su experiencia pasada y de su expectativa del mundo. Esta habilitación corresponde a la búsqueda de la mejor acomodación estable en un nicho real en el entorno, en el que pueda desarrollar ventajas termodinámicas. Se dota a la organización de un dispositivo cognitivo que proviene de su posibilidad de interactuar tanto como observador interno o externo con otros agentes, organizaciones, consigo misma y con el entorno, y de sus condicionantes dados y generados. Las capacidades, rutinas propias y el desarrollo de su particular proceso de aprendizaje, le generan una trayectoria, que habilita, potencia y limita la posibilidad de obtener, registrar y comprimir información y generar conocimiento aplicable, en tanto agregado, para su propia viabilidad.

4 Agente programado, gobernado por el funcionamiento de rutinas organizacionales, cuya posibilidad de aprendizaje es local y restringido a lo que ha sido el historial previo del agente (Teece, 1988; Teece et al, 1994). 


\subsection{Comentarios a la definición de organización}

En tanto sistema cognitivo se acoge la definición de Hernández $(2008)^{5}$. También se asume la de Gindis (2007) sobre la ontología de los grupos (sobre las suposiciones básicas que el agregado de agentes hace sobre la realidad) y epistemología (que le permite decidir sobre las prácticas del conocimiento en el aprendizaje y cuya elección determina la forma de la producción e interpretación de las teorías sobre el mundo, siguiendo a Guyot, 2005). En la definición de lo indisincrático de su proceso de aprendizaje y rutinas, se retoman varios autores, entre ellos a Teece (Teece, 1988; Teece et al, 1994), Nelson \& Winter (1982), Hodgson (2004). En la definición se reconoce que una coalición o grupo se asemeja al concepto de organización propuesto.

\subsection{La concepción de entorno}

El entorno será un agregado de organizaciones, con una estructura interna donde compiten agentes y organizaciones, y en donde se origina una personalidad característica del agregado, con una ontología propia. Así, se asume que un entorno es un sistema cognitivo con condicionantes dados y generados. Las instituciones y rutinas propias al entorno y su desarrollo de su particular proceso de aprendizaje, le generan una trayectoria, que habilita, potencia y limita la posibilidad de obtener, registrar y comprimir información y generar conocimiento aplicable, en tanto agregado, para su propia viabilidad.

\subsection{Comentarios a la definición de entorno}

En tanto sistema cognitivo, también aquí se acoge la definición propuesta por Hernández (2008). También, en la definición de lo indisincrático de su proceso de aprendizaje y rutinas, se retoman varios autores, entre ellos a Teece; Nelson \& Winter (1982) y Hodgson (2004).

\subsection{Las concepciones de decisión y sistema de interacciones}

\subsubsection{Antecedentes a la definición de decisión}

En la literatura se reconoce a la decisión como un compromiso hacia la acción (Mintzberg, 1978). Se entiende que dichas decisiones están orientadas a fines, y que parte de la iniciativa del agente que decide, es estructurar problemas bien definidos, mediante la mencionada orientación a fines (March \& Simon, 1958). También se reconoce que hay una atención secuencial a las metas, las cuales son una "materialización" de los fines, y que el proceso de "resolución" de metas, dará origen a una atención secuencial a oleadas de representación del mundo, lo que Cyert \& March (1963) denominaron "atención secuencial a la divergencia y convergencia".

La definición de Mintzberg ${ }^{6}$ resulta útil para esclarecer las nociones de estrategia pretendida y estrategia realizada, pero tiene una utilidad más limitada cuando se analiza si los compromisos para la acción

5 "Hernández (2008) argumenta a favor de la relevancia del aprendizaje organizacional. Según el autor, permite habilitar a la organización a tomar decisiones en el marco de su propia cultura -en la cual está arraigada-, y contribuye a que las acciones de coordinación deliberada entre individuos, con habilidades intrínsecamente diferentes y con procesos de aprendizaje distintos, generen trayectorias dentro de las organizaciones y sociedades, diferentes entre sí, para obtener los datos, extraer y asimilar la información y generar conocimiento aplicable. La concepción de Hernández es compatible con la de Hodgson, al identificarse en los autores que el conocimiento adquirido por el agente afectará la selección, interpretación y entendimiento que realice, y así se conformarán las trayectorias de aprendizaje (Hodgson, 2004)" (Montoya, 2010, 97).

6 Dos tipos de estrategias evidencia Mintzberg (1978): i) estrategias intencionadas (las cuales son las más recurrentes y a las que acude el modo de planeación) y ii) estrategias realizadas, las cuales el autor combina en tres maneras:

1. Estrategias intencionadas que resultan realizadas. A estas las denominan estrategias deliberadas.

2. Estrategias intencionadas que no llegan a realizarse, quizá debido a expectativas no realistas, malos juicios sobre el entorno o cambios en o durante la implementación. Estas se denominan estrategias no realizadas.

3. Estrategias realizadas que nunca fueron pretendidas, quizá debido a que ninguna estrategia fue intencionada, o vía estrategias no realizadas que fueron desplazadas; los patrones que pueden reconocerse originados de estas estrategias se denominan estrategias emergentes (Mintzberg, 1978). También resulta útil pensar en las estrategias emergentes como un patrón que surge de revisar las estrategias, cuando se presenta la emergencia de consecuencias no intencionadas. 
se traducen o no en acciones concretas, lo que puede conducir a procesos idiosincráticos diferentes, y enunciar la decisión más como un proceso o como un ente, que como un compromiso, puede favorecer una mejor comprensión de la vinculación entre decisiones y estrategia ${ }^{8}$.

Al respecto dice Stacey (1991) que, en términos de la definición, resulta mejor sugerirla estrategia como un flujo continuo de consecuencias de las acciones que los gerentes toman y de las reacciones que éstas provocan.

La definición de la decisión es relevante, no solo porque tiene implicaciones en la definición de la estrategia, sino porque contribuye a explicar la interacción entre entes.

Para la definición de decisión, va a resultar útil considerar la propiedad de los entes (agentes, organizaciones, entorno) para desempeñarse como observadores internos y externos, en un sistema representacional de interacciones. Nicolis \& Prigogine (1989) sugieren que los observadores externos describen fenómenos determinísticos y reversibles, con dinámicas invariantes, que operan bien en procesos de selección natural, y los cuales mantienen una concepción de la materia como pasiva. También sugieren que el comportamiento complejo en un sistema alude a la ocurrencia de una entre múltiples posibilidades, dada una dimensión "histórica" o memoria de eventos pasados, que toma lugar en un momento crítico y que afectará la evolución futura del sistema. Los observadores internos representan fenómenos estocásticos e irreversibles en los cuales operan procesos de auto-organización.

En este sentido se hace relevante definir un sistema representacional de interacciones, para involucrar en él la actuación de un ente con relación a otro y vislumbrar el funcionamiento de la decisión.

\subsubsection{El sistema "representacional" de interacciones}

Un sistema representacional de interacciones permite relacionar entes mediante acciones que devienen en decisiones como resultado del relacionamiento del ente con la representación o "conjetura" que se hace de otro, en particular de su estructura de "nichos representacionales".

El sistema convierte al planteamiento de una acción en decisión, cuando la acción se vincula con su posibilidad de ser puesta en ejecución, en el contexto interno (que le ofrece el sistema), el cual exhibe un comportamiento simple o complejo y de acuerdo con las representaciones que el ente se hace del sistema de interacción. Esta consideración suele implicar el funcionamiento de dispositivos de selección natural cuando se trata de comportamiento simple, $y$ de procesos auto-organizativos, cuando el comportamiento es complejo. El sistema representacional de interacciones puede también trazarse entre un ente consigo mismo, y puede generar un diálogo favorable a la generación de modelos internos.

Las interacciones se darán entre agente con sí mismo, agente- agente, agente- organización, y organización- entorno.

\subsubsection{Elementos de la definición esencial de siste- ma representacional de interacciones:}

- Usuarios: Los entes en el sistema, tales como agentes, organizaciones y entornos.

- Actores: Los mismos que en los usuarios.

- Transformación: Un sistema representacional de interacciones permite que imágenes de los entes interactúen entre ellos a través del planteamiento de la realización de una acción, cuyos productos y la acción misma, devienen en

7 Desde la noción de estrategia realizada, el autor observa que existen estrategias que fueron realizadas y pretendidas, con lo cual existe un esfuerzo deliberado en la mente del estratega para concebir y ejecutar intencionadamente sus iniciativas. Por otra parte, puede también darse la situación de estrategias realizadas que no fueron pretendidas, las cuales surgieron de forma espontánea, o como producto del seguimiento de patrones desarrollados en la ausencia de intenciones (o a pesar de ellas), denominadas emergentes" (Montoya, 2010, 39). 
decisiones identificables (lo que corresponde a la segundidad peirceana).

- Visión del mundo: El sistema representacional de interacciones podrá tener un comportamiento simple o complejo en tanto posibilidad (lo que corresponde a la primeridad peirceana), que se verá afectada por las representaciones de la dinámica simple o compleja que los entes tengan del sistema (terceridad peirceana).

- Propietario: El ente que se representa a otro en el sistema de interacciones.

- Entorno: El sistema representacional de interacciones puede hallarse dentro de otros sistemas de interacciones y dentro de alguno de los entes definidos. De hecho, cuando el sistema de interacciones es del tipo agente- agente, consigo mismo, puede presentarse la generación de modelos internos como consecuencia de la interacción en el sistema. La representación que se hace el ente del sistema sobre el comportamiento simple o complejo del sistema, va a modificar su percepción en tanto posibilidad real.

\subsubsection{La definición de decisión}

La decisión es una acción madurada en el sistema representacional de interacciones, por parte de un ente, en relación con otro. La decisión está orientada a un fin y se establece de acuerdo con los supuestos de atención secuencial a acciones. La decisión rompe la simetría de la representación simple o compleja del sistema representacional de interacciones, en tanto a que la acción que se emprende, va a afectar las posibilidades del sistema sobre la base de su proyección, condiciona la operación de la segundidad en las prácticas de conocimiento y origina verificaciones o replanteamientos de la terceridad. La presencia de una decisión va a determinar posteriormente la proyección del ente sobre su concepción del mundo de posibilidades. En resumen, la decisión resulta de la cualificación a una acción de un ente, que resulta de su valoración con relación a conjeturas de otro ente, en especial en su estructura de "nichos figurados", en el sistema representacional de interacciones. Por otro lado, la comparación entre la decisión y el espacio o estructura de nichos representados existente en un ente, va a proporcionar una información sobre el ajuste y "desempeño conceptual" del ente en el entorno.

\subsubsection{Comentarios a la definición de decisión:}

En la medida en que relaciones pueden darse entre entes, en el marco de una jerarquía de sistemas, resulta relevante señalar que la decisión está orientada a un fin, que consiste en la búsqueda del mejoramiento del ajuste de un ente en un nicho real del entorno.

En este sentido habrá decisiones de un ente con relación a sí mismo y a otros entes. En el caso de un agente, el agente podrá actuar con relación a él mismo (lo que en términos de Mintzberg se asemeja al compromiso para la acción, en tanto el agente se obliga, fruto de reflexionar o interactuar con él mismo, para actuar con otros entes), a otros agentes, a la organización y al entorno. Debido a que las acciones y decisiones van a estar orientadas a mejorar la adecuación a un nicho y se asume que un ente asume secuencialmente sus acciones, también se asumirá que un ente puede desarrollar una jerarquía de interacciones, de forma que un ente procure interactuar inicialmente con él mismo, y luego busque interactuar con un ente de jerarquía superior.

Este tipo de jerarquía marca la trayectoria del tipo de decisión hacia el "progreso", más orientada hacia una iniciativa propia del ente para mejorar su viabilidad, y lo que daría las bases para la definición de intencionalidad. Cuando primero se suceden, en un momento dado de análisis sugerido por un observador, enlaces en el sistema representacional de interacciones entre un ente de jerarquía superior y un ente inferior, y luego una relación del ente más inferior con él mismo, entonces puede aceptarse que el ente más complejo lidera la iniciativa e incide en las acciones del ente más inferior. La característica de la decisión con atención secuencial a la divergencia y convergencia, se corresponde con la proyección de posibilidades reales del sistema de interacciones con comportamiento complejo. 


\subsubsection{Comentarios al sistema representacional de interacciones}

De acuerdo con Nicolis \& Prigogine (1989), un sistema puede exhibir los comportamientos simple y complejo. También en Fraser (1975) se encuentra una clasificación detallada sobre comportamiento de los sistemas. Fraser deduce que cada nivel de integración de la materia exhibe su propia única temporalidad y que el tiempo se precisa como un aspecto de las "causalidades", las cuales animan diferentes tipos de organizaciones de lo real. Así, Fraser va a vincular la primeridad con la terceridad, mediante un argumento evolucionario según el cual señala que, "lo que ordinariamente llamamos tiempo comprende temporalidades jerárquicamente organizadas, cada una contribuyendo algo diferente a la experiencia temporal del hombre..." (Fraser, 1975, 5).

Compatibilizando las aportaciones de los autores, el comportamiento Simple que puede exhibir un sistema, y en concreto el sistema representacional de interacciones, y la manera como se integran las acciones que van a devenir en decisiones en el mismo, las cuales se realizan con base en una finalidad (la de mejorar la adaptación en la percepción de la estructura de nichos representados), puede presentarse como "acumulaciones" o agrupaciones de acciones en las jerarquías atemporal, prototemporal y eotemporal.

El punto más bajo de esta jerarquía es el atemporal, el cual caracteriza universos "acausales", en los cuales no puede identificarse la separación temporal de dos eventos, como sucede en manifestaciones del electromagnetismo (Fraser, 1975; Schwartz, 1976). Con una mayor trama de relaciones de integración de la materia, la prototemporalidad es precisada por la emergencia de partículas indiscernibles las cuales exhiben patrones en el agregado pero que de manera individual, no muestran relación causal evidente una a otra. La Eotemporalidad aparece con el desarrollo de entidades físicas más complejas las cuales, a pesar de estar conectadas unas a otras en una manera determinística de secuencia, carecen de una dirección preferente. La Eotemporalidad es una "sucesión pura" y es representada en los estados estacionarios invariantes en el tiempo o en los fenómenos cíclicos y repetitivos (Fraser, 1975; Schwartz, 1976).
En estas categorías de "coordinaciones" de eventos, que en el sistema representacional de interacciones son las acciones, el dispositivo que opera es el de selección natural. La selección involucra un conjunto anterior de acciones, cada una de las cuales interactuando con su entorno y que de alguna manera son transformadas en un conjunto posterior de acciones, donde todos los miembros del conjunto posterior son suficientemente similares a algunas del conjunto anterior, y donde las frecuencias resultantes de las acciones en el conjunto posterior dependen de sus propiedades en el contexto del sistema de interacciones (Aldrich et al., 2008). Así, a través de la selección, una población, en el caso presente de acciones, podrá gradualmente adaptarse en respuesta al criterio definido por factores de la interacción implicada. En el sistema representacional de interacciones el ente interactúa con la conjetura del "otro" y fruto de la acción como práctica de conocimiento, se modifica su concepción de posibilidades en el mejoramiento de su ajuste en un nicho que se representa del ente con el que se relaciona.

En este enfoque, los efectos de cada forma alternativa en las prácticas de conocimiento que hacen parte de los hábitos, rutinas o instituciones, en una población de entes, son mínimos y juegan un papel limitado en la determinación de las características "fenotípicas" que vienen a expresar una proyección de las posibilidades en el sistema representacional de interacciones, de forma que la selección natural suele actuar en un escenario muy determinado, sobre variaciones "heredables" muy pequeñas, las cuales pueden ser agregadas. Al darse este mecanismo, se afecta la distribución estadística de las frecuencias de formas alternativas en dispositivos de terceridad (hábitos, rutinas, instituciones en agentes, organizaciones y entornos) y la evolución resulta ser el cambio en esas frecuencias en la población, la cual constituye la colección de genes.

De acuerdo con Andrade (2003), el enfoque de selección neodarwinista deja de lado, en términos generales, las interacciones de los organismos con su entorno, subestimando la dependencia que el coeficiente de adecuación (fitness) tiene con respecto del medio ambiente.

El mérito de la propuesta teórica en este apartado consiste en la posibilidad de modelación de rela- 
ciones organismo-entorno, vía la modelación de interacciones ente-ente, mediante un mecanismo representacional, y la recuperación de la teoría de selección dentro de un enfoque sistémico, cuando la proyección del sistema de interacciones se proyecta como lineal.

Por otro lado, el comportamiento Complejo en el sistema representacional de interacciones, se va a presentar como "acumulaciones" o agrupaciones de acciones en la categoría biotemporal, siguiendo la tesis de Fraser y de Schwartz.

En la proyección Biotemporal, se alude a procesos auto-organizativos, y surge en tanto existe un cambio radical en la evolución de la materia, lo que origina la configuración de "relojes fisiológicos" asociados a señales del entorno. El proceso auto-organizativo en cuanto a la comprensión de las decisiones como mecanismo de interacción entre entes, se sucede cuando alguna acción actúa como perturbación, la cual afecta de manera débil, al azar y de forma local la textura de la representación. Una acción así, puede rápidamente desaparecer y la textura puede volver a su condición de homogeneidad. Para Nicolis \& Prigogine (1989), este comportamiento se conoce como un sistema asintóticamente estable.

Pero, en la proyección compleja, alguna perturbación puede generar un proceso de conducción o traslado el cual resulta representable linealmente. Sin embargo, una sucesión de acciones del tipo perturbaciones se pueden acumular, o una acción-perturbación puede llegar a desencadenar un rompimiento de un límite del sistema, por ejemplo, comprometer la viabilidad del ente que se representa. La superación de tal punto crítico produce la emergencia del concepto de espacio en un sistema, y se generan patrones no aleatorios. Así, el llegar a cierto punto crítico produce rompimientos en la simetría espacial (produciéndose una percepción aristotélica del espacio) y temporal (pues se genera un patrón de oscilaciones al interior del sistema).

Nicolis \& Prigogine (1989) van a sugerir que resulta posible observar patrones regulares en espacio y tiempo en la forma de olas propagatorias:
- Sobre distancias macroscópicas, y

- $\quad$ Sin distorsiones y a velocidades definidas.

Para los autores, es legítimo preguntarse si algunas de las características exhibidas por los sistemas biológicos pueden ser atribuidas a transiciones inducidas por restricciones alejadas del equilibrio y mecanismos desestabilizadores apropiados similares a la autocatálisis química. Finalmente, si el proceso de la perturbación es acelerado, se posibilita la evolución de transiciones a nuevos tipos de comportamiento.

En estas representaciones, dice Fraser que los conflictos surgidos en un nivel de representación pueden ser resueltos mediante regresión o por la emergencia de un nivel de concepción temporal. Así, un ente puede ser transportado al nivel eotemporal por la repetición obsesiva compulsiva la cual transforma su trayectoria de decisiones en un ritual adireccional y atemporal, mientras que en el nivel biotemporal, un ente puede realizar una transformación profunda de sus estructuras (segundidad) y desarrollar las consecuencias de esta transformación.

Este marco de análisis permite variedad en la clasificación de decisiones, de forma que se aprecia cómo decisiones van a resultar dramáticas y transformacionales en condiciones de comportamiento complejo del entorno, mientras que en contextos lineales van a resultar incrementales o incluso, triviales. También se favorece la posibilidad de clasificar decisiones por acción del entorno sobre el ente o del ente sobre otro ente, con lo cual se puede empezar a configurar parte del problema de la intencionalidad en la estrategia y su carácter voluntario o involuntario.

El carácter esencial de la decisión es su papel como elemento que rompe la simetría de un sistema representacional de interacciones, pues implica la decisión como producto del sistema representacional, que el relacionamiento con el ente "personificado", eventualmente va a configurarse con una nueva trayectoria, que puede modificar por completo la forma de interactuar con el ente, tanto representacionalmente, como en el mundo de las acciones "reales". 
Por último, el sistema representacional va a vincularse con un sistema real de interacciones, a través del dispositivo cognitivo del que dispone cada ente.

\subsection{Los nichos representacionales y reales}

\subsubsection{Antecedentes a la definición de nicho}

Para Kauffman (2003) las formas de ganarse la vida, constituyen los nichos que las poblaciones de organismos, en proceso de especiación y diversificación, serán capaces de ocupar y dominar. Las formas de ganarse la vida que presenten relieves adaptativos del tipo de los que pueden ser explorados mediante los procedimientos de que disponen los organismos serán, obviamente, las que perduraran como tales. Así, los organismos, sus nichos y los procedimientos de búsqueda se construyen unos a otros conjunta y auto-consistentemente.

Observa Kauffman que entes complementarios han de ser empleados conjuntamente para crear valor mientras que los sustitutivos se reemplazan entre sí. Por ejemplo, los complementarios y sustitutivos de cualquier bien o servicio constituyen el nicho económico en el que dicho bien o servicio "vive". Habitualmente, los nuevos bienes hacen su aparición en la economía como complementarios o sustitutivos de otros ya existentes (Kauffman, 2003).

En Holland (2004), la persistencia de cualquier agente individual, depende del contexto proporcionado por otros agentes. Sugiere el autor que cada clase de agente llena un nicho, el cual es definido por las interacciones que se centran sobre el agente. Cuando agentes desaparecen de un nicho, vendrán otros a llenar el hueco, lo que representa un fenómeno similar al llamado convergencia en biología. También anota que surge diversidad cuando la propagación de un agente abre un nuevo nicho, entendido el nicho como oportunidades para nuevas interacciones, que puede ser explotado por las modificaciones de otros agentes y que este proceso es el que sucede con el mimetismo. Así, el autor anota para los sistemas complejos adaptables que la diversidad resulta ser un patrón dinámico, a menudo persistente, coherente y evolutivo.
Finalmente, sugiere Holland que, durante su búsqueda de patrones de comportamiento diferentes, un agente puede presentar un mecanismo con un significado funcional bien definido, el cual abre nuevos nichos para otros agentes y que existen procesos de convergencia que se refieren a la similitud de los agentes que ocupan nichos similares. A la larga, van a surgir en tales nichos nuevas variantes en donde hay muchos agentes, ya que más ejemplares significan más posibilidades de variación (Holland, 2004).

\subsubsection{Definición de nicho representacional}

Un nicho representacional es una forma de concebir, bajo un enfoque preciso, suposiciones básicas sobre la estructura de la realidad y una forma de actuación del ente, en otro ente. Un nicho representacional puede ser definido también, siguiendo la definición anterior, y de manera externa al ente, como un espacio conceptual en la estructura del ente representado, en el cual resulta probable encontrar enfoques precisos y formas de actuación de otros entes de jerarquía inferior. La concurrencia de entes y sus enfoques precisos en tanto resultan complementarios o sustitutos favorecen un proceso de competencia y la superposición da una dimensión del ajuste perceptual entre entes. Cada apertura de un nicho posibilita nuevas interacciones y concurrencia. Un nicho representacional es una definición puntual de un procedimiento de búsqueda de un ente para lograr un mejor ajuste en un nicho real, que puede tener un carácter dinámico.

\subsubsection{Definición de un nicho real}

Siguiendo a Kauffman (2003), un nicho es una forma de ganarse la vida, o una forma de actuación de un ente, dentro de otro ente. En ese sentido, el llenar un nicho real implica el uso de recursos y redes de elementos de un ente, por parte de otro ente que actúa en el primero. Éste último realizará, al menos, un ciclo de trabajo que le permita mantenerse viable en su interconexión dinámica con su contraparte, por lo que tendrá que retribuirle también, en tanto la preservación del nicho va a depender de las interacciones que establezca el ente que realiza el trabajo en el sistema real de interacciones. 


\subsubsection{Comentarios a las definiciones}

La decisión viene a realizar un rompimiento en la simetría espacial y temporal en la representación de la estructura del ente que incorpora a uno de jerarquía inferior. Cada ente tiene una estructura conceptual de espacios que se generan con las novedades producidas por las decisiones, y una estructura de interacciones producidas por las actuaciones de entes en un sistema real de interacciones. Estas estructuras están conformadas por nichos, tanto representacionales como reales.

Un nicho representacional es una forma de concebir bajo un enfoque preciso, suposiciones básicas sobre la estructura de la realidad y una forma de actuación con base en cómo enmarcar las problemáticas. Por su parte, un nicho real es la forma de actuación en el mundo real, propiamente dicha, que implica una articulación del proceso de producción del ente con una red productiva de otro ente. El nicho representacional se constituye en una "tecnología", la cual describe cómo un ente decide y cómo piensa actuar, $y$ esa forma le genera condicionamientos y posibilita mejoramientos en la viabilidad del ente.

La novedad en las representaciones, y en las actuaciones va a ser jalonada por la conformación de nichos (representacionales o reales) y por la sustitución y complementariedad de enfoques precisos y actuaciones, respectivamente. La proximidad entre enfoques y actuaciones produce la posibilidad de convergencia y acumulación, y favorece la exploración de nuevas viabilidades adyacentes posibles.

Dependiendo de la visión de mundo desde la cual se represente y configure el nicho representacional, éste, "comienza a adquirir un significado" (Checkland \& Scholes, 1994). La delimitación de un nicho representacional estará dada por un ente desde una particular condición de observación de la realidad. El ente establece una interpretación, y le confiere una estructura y unas características particulares al mismo. Esta configuración, se encuentra atribuida al conocimiento basado en la experiencia de dicho ente. Cada nicho representacional se convierte en un producto figurativo histórico que expresa características de las interrelaciones internas del ente, lo que le confiere una identidad propia que involucrará luego en su actuación, en las formas de producción y una red de instituciones y formas de organización que se encargarán de darle cohesión a los elementos del ente.

Las variaciones en la representación o actuación con respecto a los nichos, van a generar trayectorias que tejen la estructura interna de cada ente.

\subsection{El sistema real de interacciones}

\subsubsection{Definición del sistema real de interacciones}

Un sistema real de interacciones permite relacionar entes mediante decisiones que devienen en actuaciones como resultado del relacionamiento "corpóreo" del ente con otro.

El sistema convierte al planteamiento de una decisión en actuación, cuando la decisión es ejecutada por un ente, con relación a otro, en el contexto interno (que le ofrece el sistema real de interacciones), el cual exhibe un comportamiento simple o complejo. Esta consideración suele implicar el funcionamiento de dispositivos de selección natural cuando se trata de comportamiento simple, y de procesos auto- organizativos, cuando el comportamiento es complejo. El sistema real de interacciones puede también trazarse entre un ente consigo mismo, y afecta el mundo material y energético de los entes, así como su estructura de actividades, procesos y presiones. En resumen, afecta su proceso de producción de sí.

Las interacciones se darán entre agente con sí mismo, agente-agente, agente-organización, y organización-entorno.

Por último, el sistema representacional va a vincularse con un sistema real de interacciones, a través del dispositivo epistemológico ontológico del que dispone cada ente.

\subsubsection{Elementos de la definición esencial de sistema real de interacciones:}

- Usuarios: Los entes en el sistema, tales como agentes, organizaciones y entornos. 
- Actores: Los mismos que en los usuarios.

- Transformación: Un sistema real de interacciones permite que los entes interactúen entre ellos a través de sus redes de actividades, cuyos productos y la decisión misma, devienen en actuaciones identificables.

- Visión del mundo: El sistema real de interacciones podrá tener un comportamiento simple o complejo en tanto posibilidad (lo que corresponde a la primeridad peirceana), que se verá afectada por las condiciones de dinámica del ente. Usualmente, un ente de jerarquía superior se representará él mismo, con un comportamiento simple o complejo.

- Propietario: El ente que actúa en el sistema real de interacciones.

- Entorno: El sistema real de interacciones puede hallarse dentro de otros sistemas de interacciones y dentro de alguno de los entes definidos.

\subsubsection{Comentarios al sistema real de interacciones}

De acuerdo con la aportación previa del sistema representacional de interacciones, se aprecia que el sistema real de interacciones puede exhibir igualmente comportamientos simple y complejo. El comportamiento simple en el sistema real de interacciones alude a cómo se integran las decisiones que van a devenir en actuaciones en un ente, con relación a la propuesta del ente que decide. El dispositivo que opera es el de selección natural. La selección involucra un conjunto anterior de actuaciones, cada una de las cuales relacionadas con una red de interacciones y que de alguna manera son transformadas en un conjunto posterior de actuaciones, donde todos los miembros del conjunto posterior son suficientemente similares a algunas del conjunto anterior, y donde las frecuencias resultantes de las acciones en el conjunto posterior dependen de sus propiedades en el contexto del sistema real de interacciones (siguiendo a Aldrich Et Al., 2008). Así, a través de la selección, una población, en el caso presente de actuaciones, podrá gradualmente adaptarse en respuesta al criterio definido por factores de la interacción implicada en la red de actividades, procesos y condicionantes. En el sistema real de interacciones, el ente interactúa con la red de actividades (que configura su proceso de producción) del "otro" y como resultado de esa actuación, la que adelanta mediante la ejecución de al menos un ciclo de trabajo termodinámico, se modifica su viabilidad termodinámica y su ajuste en un nicho real. En este enfoque, los efectos de cada actuación, condicionada por los hábitos, rutinas o instituciones, procesos y recursos, en una población de entes, son mínimos y juegan un papel limitado en la determinación de las características "fenotípicas" que vienen a expresar una adecuación en el sistema real de interacciones, de forma que la selección natural suele actuar en este sistema, en un escenario muy determinado, sobre variaciones "heredables" muy pequeñas, las cuales pueden ser agregadas. Al darse este mecanismo, se afecta la distribución estadística de las frecuencias de formas alternativas en dispositivos de terceridad (hábitos, rutinas, instituciones en agentes, organizaciones y entornos) y la evolución resulta ser el cambio en esas frecuencias en la población, la cual constituye la colección de genes.

Por otro lado, el comportamiento complejo en el sistema real de interacciones, alude a que una sucesión de actuaciones del tipo perturbaciones se puedan acumular, o que una actuación -perturbación pueda llegar a desencadenar un rompimiento de un límite del sistema, por ejemplo, concentrar la capacidad productiva del ente con el que interactúa. La superación de tal punto crítico produce la emergencia del concepto de espacio en un sistema, y se generan patrones no aleatorios. Así, el llegar a cierto punto crítico produce rompimientos en la simetría espacial y temporal de la estructura de los nichos reales en el ente respectivo. Si el proceso de la perturbación es acelerado, se posibilita la evolución de transiciones a nuevos tipos de comportamiento. Este marco de análisis permite variedad en la clasificación de las actuaciones. Algunas van a resultar dramáticas y transformacionales en condiciones de comportamiento complejo, mientras que en contextos lineales van a resultar incrementales o incluso, triviales. También se favorece la posibilidad de clasificar actuaciones por acción del entorno sobre el ente o del ente sobre otro ente, con lo cual se puede empezar a configurar parte del problema de la intencionalidad en la estrategia y su carácter voluntario o involuntario. 
Es conveniente señalar que la actuación rompe la simetría de la estructura de producción de un ente.

\subsection{La actuación}

\subsubsection{Definición de actuación}

Una actuación es una decisión realizada en el sistema real de interacciones, por parte de un ente, en relación con otro. La actuación está orientada a un fin, que es el de mejorar de manera dinámica la ubicación en un nicho real de un ente, que realiza al menos un ciclo de trabajo. La actuación rompe la simetría de la representación simple o compleja del ente y su red de actividades, en tanto a que la actuación que se emprende, va a afectar las posibilidades del ente al condicionarse su operación de actividades, procesos y presiones, y lo que va a originar verificaciones o replanteamientos de su forma de representarse el mundo (Terceridad periceana). Una actuación va a determinar posteriormente la proyección del ente sobre su concepción del mundo de posibilidades. En resumen, la actuación resulta de la cualificación a una decisión de un ente, que resulta de su valoración con relación a conjeturas de otro ente, en especial en su estructura de "nichos reales", en el sistema real de interacciones. Por otro lado, la comparación entre la actuación y el espacio o estructura de nichos reales existente en un ente, va a proporcionar una información sobre el ajuste y "desempeño real" del ente en el entorno.

\section{La concepción de estrategia y reconoci- miento de las visiones del mundo de las nociones estrategia deliberada y estrate- gia emergente.}

La estrategia en términos de producto, y como concepto para su aplicación general, se reconoce como la concepción de la declaración de la ubicación de un agente u organización en un entorno, sobre una representación del mundo. Esta noción implica un proceso mediante el cual un ente posibilita su viabilidad en un entorno cambiante y se concebirá la problemática de la estrategia de un ente sistema abierto, como asociada a la relación circular con el entorno, la cual implica las dimensiones de las actividades que le generan competencia y su valoración, sus procesos y la generación de su institucionalidad propia e identidad. Nociones de esta concepción de estrategia fueron reconocidas por Mintzberg (1978); Hatten (1999); Montoya (1999); Montoya \& Montoya (2003); Montoya \& León (2004); y Montoya (2010).

En un nivel más detallado, la estrategia "intencionada" se desarrolla por entes en el sistema representacional de interacciones, o en el sistema real, y corresponde a algún patrón identificable en el flujo de las acciones que devienen en decisiones o actuaciones y que está en consonancia con la percepción del mundo.

Los patrones iniciales identificables se relacionan con la concordancia entre una decisión o actuación del ente en el sistema de interacciones con otro o él mismo, y que conduce a otra decisión o actuación del ente, con otro semejante o de jerarquía superior, de manera posterior.

Una estrategia intencionada básica, representacional, se puede explicar inicialmente como la concordancia entre una decisión del ente, en relación a sí mismo en el sistema representacional de interacciones, que se traduce en una acción "coherente" del ente con otro superior en el sistema representacional de interacciones. La coherencia tiene que ver, como se explicará más adelante, en la conformidad y armonización entre primeridad, segundidad y terceridad en el proceso de representación y actuación del ente.

Una intencionalidad "directiva" será la proveniente de la concordancia entre una decisión de un agente con la organización, que deviene en una decisión o actuación "coherente" de la organización con el entorno.

El empleo de la palabra "estrategia", como se hace comúnmente, alude a una declaración "estática" en un momento dado, del problema de declarar una decisión o actuación de un ente con respecto a otro en el sistema representacional o real de interacciones, con una visión del mundo particular y un propósito dado, que corresponde al de mejorar su ubicación en un nicho real en el entorno, o el de interactuar consigo mismo. Usualmente coincide también con el patrón identificado en un proceso de interacción del ente consigo mismo, que se traduce o resulta cohe- 
rente con otra decisión posterior del ente con un ente de jerarquía superior.

La percepción del mundo que asumen los entes, sobre la cual realizan acciones (y dentro de las acciones realizan prácticas de conocimiento), que incorporan a sus dispositivos de retención y que proyectan para interpretar nichos reales y sus posibilidades, se elabora inicialmente a través del ejercicio del relacionamiento en el sistema representacional de interacciones. En ocasiones alguna acción-perturbación podrá resultar crítica para transformar la segundidad y terceridad del ente, el cual podrá redefinir su aprendizaje y proyectar nuevas suposiciones sobre las posibilidades reales. Sin embargo, una buena parte de los entes lo que hacen es reinterpretar la información de las actuaciones en términos de la proyección vigente, lo que puede resultar en sesgos en el proceso cognitivo, y que el ente protege con refuerzos en reafirmaciones de la proyección vigente en los dispositivos de retención (como sucede en el caso de la cultura o de la ontología del grupo).

En parte esto se debe a que los entes acogen en su segundidad un método heurístico para atenuar el volumen de los flujos de interacciones, el cual repercute en su terceridad en tanto aprendizaje y conocimiento del mundo, dado que la creación de modelos específicos para cada interacción como esquemas, resultaría un acervo inmenso y costoso de procesar, codificar, retener y emplear. Así, los entes se hacen particularmente sensibles a registrar de otros entes, bien por vía del sistema representacional, o por el sistema real de interacciones, informaciones que coinciden con su forma de retenerlo y proyectarlo, y a descartar manifestaciones que no corresponden con su sistema de retención. Estos métodos heurísticos, reconocidos por los autores como marbetes, y en el presente caso, aquellos que refuerzan la representación ontológica y las prácticas, ofrecen economías en los procesos. También puede proponerse la conformación de un "paquete" completo coherente, que puede denominarse coherencia polar. Se denomina de esta manera porque las coherencias polares tienen como referente enfoques dialécticos sobre el funcionamiento del mundo que se asemejan a la preferencia general por la aversión al cambio y las innovaciones, y van hacia el conservadurismo o el liberalismo. Esta propuesta se origina en el esfuerzo integrador que hacen los entes por hacer corresponder sus prácticas de conocimiento con los hábitos, rutinas o instituciones del ente (según sea la situación), lo que los conduce a recoger información externa que coincide con su percepción del mundo, y refuerzan su representación ontológica previa.

Los patrones de actuaciones tienen diferencias elocuentes en tanto se representa el mundo desde una perspectiva de simplicidad, como si se hace desde la complejidad. El modelamiento que ofrecen la mayoría de los autores suele acoger solamente una de estas perspectivas, y se realizan ejercicios de representación que no posibilitan diversas prácticas de conocimiento y actuaciones para los agentes cognitivos que emplean, por lo que resulta una innovación el habilitar esta posibilidad, inspirada en Andrade (2003).

En ese sentido, puede decirse que, dado que se asume la existencia de entes que proyectan entes del sistema real de interacciones, en nichos representacionales en el sistema representacional de interacciones, y cuyas decisiones se aplican en el sistema real de interacciones, cuyo ajuste retroalimenta la percepción del ente sobre posibilidad de interacciones, se pueden nombrar dos sistemas de formación de la estrategia, uno cuya cosmovisión del ente obedece a representarse el mundo como uno deterministico-lineal, y otro como de comportamiento complejo. En el primero funcionará un mecanismo de selección natural, mientras que la generación de variedad corresponde a mutaciones en los artefactos de retención en los entes que hacen parte de la población, y los entes exhibirán un comportamiento de observadores externos al estilo del demonio de Laplace ${ }^{8}$.

8 "Laplace concibió un ser demoníaco, capaz de conocer la posición y velocidad de todas las partículas del Universo en un momento dado, y de resolver las ecuaciones de Newton en el ámbito de su aplicación universal. Este ser sería conocedor del acontecer de todo lo que existe, en cualquier momento en la historia del tiempo. La imagen más sencilla del demonio de Laplace evoca a San Pedro, sobre una nube, leyendo en el gran libro de la vida de todos los seres, para cualquier momento imaginable en el tiempo, viendo desde allí a los seres del universo, cumplir inexorablemente con lo designado" (Montoya, 2010, 58). 
Por su parte, en el de comportamiento complejo, se supone que opera un dispositivo auto-organizativo dentro de la noción de agentes autónomos, desde una perspectiva de observadores internos al estilo del demonio de Maxwell9.

\section{Enunciación de los sistemas "estrate- gia deliberada" y "estrategia emergente"}

En tanto la estrategia es un patrón reconocible en el flujo de decisiones o actuaciones, se pueden apreciar diferentes posibilidades de estrategias. Aquí se han mencionado las estrategias intencionadas, que van a corresponder con estrategias deliberadas, las cuales han sido definidas por Mintzberg como pretendidas y realizadas. Como se apreciará en la siguiente sección, la definición de intencionalidad conduce a la realización, bien de prácticas de conocimiento o de actuaciones en una red de actividades y procesos del mundo real. Por lo tanto, la intencionalidad se corresponde con una realización en el sistema representacional o en el sistema real de interacciones, y así, las estrategias intencionadas en tanto son patrones, se traducen en estrategias deliberadas.

Es así como se prefiere hablar de una estrategia intencionada representacional y una estrategia intencionada realizada preferentemente. En cuanto a estrategias realizadas, hay dos posibilidades, acogiendo la noción que las estrategias realizadas tienen que ver con transformaciones en el mundo real:

- Aquellas que provienen de la actuación de un ente consigo mismo.

- Las que resultan de la actuación de un ente con otro.
Buena parte de la dificultad en la definición de estrategia emergente que existe en la literatura, es que se la vincula a una estrategia realizada, sin poder apreciar si existen patrones o no que indiquen su posibilidad de origen o identificación. En las definiciones de estrategia emergente, se alude a casi cualquier estrategia realizada que no fue intencionada y que resultó efectuándose, lo que resulta restrictivo en la comprensión de la problemática.

\subsection{Definición del sistema "estrategia deliberada" ED}

El sistema ED es un sistema de actividad de un ente autónomo, con propósito último definido en términos del mejoramiento de su adecuación a un nicho real en donde pueda desarrollar de manera eficiente su ciclo de trabajo termodinámico, el cual permite al ente obtener como producto una declaración de su ubicación en relación con otro ente o en un entorno, mediante el reconocimiento de un patrón de intencionalidad en una acción o práctica a emprender, desde su visión del mundo y sus prácticas de conocimiento, que corresponden a identificar el mundo de posibilidades, o el mundo real, como interpretable desde una perspectiva de la simplicidad y con orientación deductiva. El sistema ED implica una interacción de segundo nivel, pues requiere de la identificación de un patrón, el cual se establece como el que surge de la coherencia entre una interacción previa del ente, usualmente consigo mismo y una decisión o actuación posterior del ente con otro.

Una identificación de una estrategia deliberada (ED), suele hacerse relativamente fácil, cuando el ente exhibe coherencia polar definida. De hecho, la posibilidad de pronosticar las actuaciones futuras de un agente, se hace con base en la proyección de dicha coherencia. La existencia de coherencia po-

\footnotetext{
9 "Maxwell concibió otro ser demoníaco, para ayudar a explicar cómo podría eludirse el cumplimiento de la segunda ley de la termodinámica. Este demonio sería una criatura capaz de actuar a nivel molecular seleccionando moléculas calientes y moléculas frías de un gas, para luego separarlas y poder así extraer trabajo. La segunda ley de la termodinámica prohíbe que entre dos cuerpos a diferente temperatura se pueda transmitir el calor del cuerpo frío al cuerpo caliente. Un ejemplo real de demonio de Maxwell es la existencia de proteínas en la membrana celular, las cuales logran ordenar los iones a ambos lados de la membrana citoplasmática, para así garantizar ciertas respuestas celulares. El demonio trabaja de manera "interesada" y debe invertir energía para tener capacidad de decisión, que es la que se emplea para lograr la separación de partículas a nivel molecular. El ejemplo más sencillo para reflexionar sobre este concepto es un molino de viento que detecta la dirección de las corrientes de aire, frías y calientes, y aprovecha su capacidad de movimiento para extraer trabajo aprovechable" (Montoya, 2010, 58).
} 
lar, como un "paquete" integrado, le permite a otros agentes completar vacíos en la información sobre la posibilidad de desempeño de un agente, por lo que, suponer que un ente puede entenderse por la noción de coherencia polar, suele facilitar la integración entre agentes, y reduce considerablemente el tiempo de interpretación de otros entes, con un riesgo relativamente pequeño de equivocaciones.

Serán estrategias pretendidas, y en tanto se perciben como patrones, serán deliberadas, las que se relacionan con la concordancia entre una decisión o actuación del ente en el sistema de interacciones con otro o él mismo, y que conduce a otra decisión o actuación del ente, con otro semejante o de jerarquía superior, de manera posterior, evidenciando su intencionalidad. Así, se tienen varios tipos de estrategias pretendidas:

- La decisión representada por un ente consigo mismo, que luego resulta en una decisión representada por el ente con otro (PretendidaPretendida). Esta es una estrategia deliberada representacional pura.

- La decisión representada por un ente consigo mismo, que luego resulta en una actuación real por el ente con otro (Pretendida-Realizada) Este tipo de patrón en las decisiones es el que Mintzberg alude como estrategia deliberada y corresponde a una estrategia deliberada realizada.

- La actuación de un ente consigo mismo, que luego resulta en una actuación real por parte del ente con otro (Realizada-Realizada), y que dado el procedimiento de búsqueda, resulta intencionado. Esta estrategia puede denominarse estrategia deliberada realizada pura y alude normalmente a una interacción tácita representacional previa del ente, consigo mismo.

- La actuación de un ente consigo mismo, que luego resulta en una decisión representada por el ente con otro (Realizada-Pretendida). Esta estrategia alude a una estrategia deliberada preparatoria, pues suele ser la antesala a una nueva interacción en el sistema real de interacciones por parte del ente.
Entre estas estrategias resulta posible sugerir ciclos de articulación. Las formas de articulación de estos tipos proveen un marco de reflexión sobre la idiosincrasia de las prácticas de conocimiento y actuación de los entes.

Resulta de la mayor relevancia señalar que en la estrategia deliberada, las representaciones del comportamiento de los entes corresponden al paradigma de la simplicidad, debido a que se representan la interacción con otros entes, a la manera de un demonio de Laplace, en donde el observador es externo a la relación sistema-entorno, y posee de manera determinística una ecuación o representación con la cual puede explicar o pronosticar para cualquier momento de tiempo el estado del desempeño del ente (Popper, 1986). La información es considerada como algo real, que se percibe y puede medirse, que existe en el mundo físico independientemente de los sistemas observadores y sin requerir una explicación de su funcionalidad y/o aplicabilidad.

En esta situación, el observador externo posee una representación poderosa sobre cómo funciona su universo, de manera que mide y registra información del entorno y la "decodifica" y comprime para la elaboración de planes, privilegiando aquella que corresponde a su representación ideal del mundo y verificándola al ejecutar sus acciones.

Estas representaciones suelen aplicarse bien al terreno de la cercanía al equilibrio, mediante representaciones lineales de los procesos de cambio y/o ajuste. Una particularidad de este tipo de proceso ontológico y epistémico es que el observador externo no necesita utilizar los resultados para producir cambios funcionales en el sistema objeto de medida, de forma que opera un mecanismo de selección que se hace mecánico y predominante (Andrade, 2003). La ocasión de la intencionalidad, que corresponde a un momento previo a la decisión o la actuación, es lo que configura la imagen de las interacciones en los sistemas representacional o real como determinísticas realizadas por un observador externo.

Así, la ED es un patrón que se relaciona con la concordancia entre una decisión o actuación del ente en el sistema de interacciones con otro o él mismo, 
y que conduce a otra decisión o actuación del ente, con otro semejante o de jerarquía superior, de manera posterior, evidenciando su intencionalidad.

\subsubsection{Elementos de la definición esencial de la ED:}

- Usuarios: El ente del sistema en un primer momento, y el ente con otro en un momento posterior.

- Actores: Los mismos que en los usuarios.

- Transformación: Un sistema ED cubre al menos dos sistemas de interacciones con el propósito de definir intencionalidad.

- Visión del mundo: En el sistema ED el ente opera con un dispositivo ontológico- epistemológico que proyectará sobre el mundo real y que se constituirá en su mundo real, desde una perspectiva de lo simple.

- Entorno: El sistema ED se encuentra inmerso en los sistemas de interacciones representacional y real, y va a encontrarse dentro de otros sistemas de interacciones y dentro de alguno de los entes definidos.

\subsection{Definición de "estrategia emergente" EE}

El sistema EE es un sistema de actividad de un ente autónomo, con propósito último definido en términos del mejoramiento de su adecuación a un nicho real en donde pueda desarrollar de manera eficiente su ciclo de trabajo termodinámico, el cual permite obtenerse como producto una declaración de su ubicación en relación con otro ente o en un entorno, que no necesita del reconocimiento de la intencionalidad en una acción o práctica a emprender, desde una visión del mundo y sus prácticas de conocimiento correspondiente a la de observadores internos, dentro de una perspectiva de complejidad.

Serán estrategias emergentes "precarias", las que desde un punto de vista de observadores internos, vinculan una actuación, de un ente con otro, en los sistemas de interacciones. Allí, apenas se empieza a vislumbrar un flujo que podrá más adelante configurar una estrategia deliberada bien conformada.
Las estrategias emergentes "auténticas", son patrones observables quee vinculan una actuación por parte de un ente con relación a sí mismo, que se traduce en una actuación del ente con otro, desde una perspectiva de observadores internos, lo que significa que el ente buscará en el sistema de interacciones posibilitar su viabilidad en términos termodinámicos de manera local, en un momento determinado. Las estrategias emergentes "complejas" serán patrones observables en periodos de tiempo relativamente largos, de estrategias emergentes precarias o "auténticas", dentro de una concepción de comportamiento de complejidad en los sistemas de interacciones que se involucren, que se van acumulando y resultan en una perturbación mayor que se acelera, debido a la colección de decisiones o actuaciones, que puede generar un proceso transformacional "emergente" de la estructura del ente involucrado. Procesos de revolución o transformación social son ejemplos de este tipo de estrategias.

Debe hacerse hincapié en afirmar que, en la estrategia emergente, las representaciones del comportamiento de los entes corresponden al paradigma de la complejidad, dentro de una representación de la interacción con otros entes, a la manera de un demonio de Maxwell, lo que significa que el ente es un sistema observador local interno (Bennett, 1987) que busca ejecutar mediciones, procesar la información adquirida y usa los resultados para actuar con el objetivo de optimizar la cantidad de trabajo que puede ser realizado, de manera que puedan surgir procesos auto-organizativos, que habiliten, limiten y potencien los procesos de selección (Kauffman, 1993).

Zurek (1989) propone que el estimado de la cantidad de energía interna que puede ser convertida en trabajo útil por acción de un agente como el propuesto, debe definirse como "entropía física". En este caso, la información adquirida se utiliza para sobrevivir, en íntima relación con las funciones y significación de las estructuras (Bennett, 1987; Zurek, 1989 citado en Andrade, 2003). Normalmente, un observador interno se encuentra ya en medio de la ejecución de una actuación, que previamente desarrolló, por lo general, como una estrategia intencionada. Desde la perspectiva de observadores internos, el ente no 
tiene posibilidades de confrontarse con un sistema representacional, por lo que solamente va a tener posibilidad de viabilizar su permanencia en el nicho real, a través de extraer energía aprovechable para realizar su ciclo de trabajo.

\subsubsection{Elementos de la definición esencial de la EE:}

- Usuarios: El ente del sistema, restringido en su posición de observador interno. También un ente agregado, dentro de un periodo de tiempo relativamente largo.

- Actores: Los mismos que en los usuarios.

- Transformación: Un sistema EE implica la posibilidad de mantenerse viable en un nicho real, extraer energía de la red de actividades y procesos del ente en donde se encuentra el nicho real y posibilitar el desarrollar ciclos de trabajo de un ente "observador interno".

- Visión del mundo: En el sistema EE el ente opera con un dispositivo ontológico- epistemológico, desde una perspectiva de lo complejo, como observador interno.

- Entorno: El sistema EE se encuentra inmerso en el sistema de interacción real, y en los entes con nichos reales.

\subsection{Las ventajas de definir ED y EE en términos de sistemas}

Mintzberg (1987) señala que hay una gran diversidad en el concepto de estrategia ${ }^{10}$. Se la concibe como un plan (una serie de cursos de acción conscientemente pretendidos a manera de guía), como una "estratage- ma" o "engaño", pensado para alardear y permiten al realizador posar en la ejecución de iniciativas que no van a realizarse pero que sugieran a los rivales amenaza o disuasión, en situaciones de negociación con asimetrías en información, o tamaño. También se alude a la estrategia como una posición (reconocer acciones y fuerzas mediadoras entre la organización y su entorno, de forma tal que la estrategia resulta ser un "nicho" que permite la generación de rentas). Igualmente se la identifica como un patrón, o una forma de conducta predeterminada característica en el tiempo, y como una perspectiva, la cual orienta y da coherencia a las actuaciones de la organización en el tiempo. En casi todas estas definiciones la estrategia es tratada como explícita, desarrollada desde un propósito y de manera consciente, y realizada con anticipación a una decisión específica a la cual aplica.

Por otra parte, la estrategia emergente se sugiere en la literatura como un proceso incremental de prueba $y$ error, en el que se privilegia cierta amplitud del enfoque general de la organización en cuanto a su posibilidad de transformación del entorno, y sus políticas y objetivos ${ }^{11}$. En la idea de estrategia emergente, se busca ex-post una orientación general de decisiones y acciones emprendidas para preservar posiciones de interés, y las orientaciones que se hacen coincidir con el enfoque ideológico del individuo o grupo preponderante. Sin embargo, no hay teorías desarrolladas que expliquen adecuadamente la procedencia de la estrategia emergente.

La definición de los sistemas "estrategia deliberada" y "estrategia emergente" vienen a esclarecer buena parte de esta multiplicidad de concepciones sobre lo que se entiende por estrategia. De igual manera sucede con la estrategia emergente, la orientación ontológica-epistemológica del ente en

10 Mintzberg (1987) acopia buena parte de la diversidad en el concepto y empieza por reconocer que una de las alusiones más evidentes a la palabra estrategia consiste en concebirla como un plan, el cual en sus palabras es una serie de cursos de acción conscientemente pretendidos a manera de guía, con los cuales interviene o interactúa sobre una situación. Los planes, en su opinión, poseen como características que son desarrollados conscientemente y sobre la base de un propósito, además de realizarse de manera anticipatoria a las acciones para las cuales aplican.

11 Otra manera de aludir a la estrategia es entenderla como una posición, es decir, reconocer acciones y fuerzas mediadoras entre la organización y su entorno, de forma tal que la estrategia resulta ser un "nicho" que permite la generación de rentas (donde normalmente existe un dominio de actividad "producto-mercado") fruto de lograr copar el mercado o el segmento y lograr evadir la competencia (Mintzberg, 1987). Este esfuerzo resulta normalmente de un ejercicio anticipatorio pero también podría proceder de un patrón de comportamiento de un actor específico. 
su condición de observador interno, y su operación en un sistema "real" de interacciones, que afecta, entre otros dispositivos, la forma de representación posterior del ente.

En realidad, todas las definiciones que se encuentran en la literatura, aluden a algún momento en el relacionamiento del ente con los sistemas de interacción representacional y real, de donde se desprenden los sistemas "estrategia deliberada" y "estrategia emergente" como corolarios de dichos procesos de articulación. La noción de plan alude a una estrategia deliberada "realizada", mientras que la de posición y estratagema, tienen que ver con un enfoque genérico de sistemas, que en lo expuesto se exhibe en la relación del ente con el sistema de interacciones. En cuanto a patrón, se hace lo propio en las definiciones de las estrategias deliberadas y emergentes, y resulta visible que la perspectiva de observadores externos o internos, es un aspecto crucial para la definición del problema de la decisión y la formación de la estrategia. Así, el marco propuesto por la presente propuesta, si bien es restrictivo en incluir variados elementos, ofrece un planteamiento que hace compatibles en una sola conceptualización la variedad del concepto.

Por último, las teorías de estrategia alrededor del enfoque de posicionamiento han hecho hincapié en la identificación de estrategias genéricas en industrias. La definición de una industria, criticada por ser poco específica en la literatura, alude en la presente propuesta a la idea de nichos coincidentes, por lo que una identificación de una industria puede ser representacional o real. Las estrategias genéricas se apalancan en la búsqueda de extremos explicativos en el espacio de la estructura de nichos en un sistema de interacciones, generalmente uno representacional.

El sistema representacional incorpora en la propuesta el rol que le dan teóricos al papel de la identificación de nichos, mientras que por otra parte, el sistema real de interacciones, alude a los enfoques de recursos y capacidades.

\section{Enunciación de modelos conceptuales para explicar la formación de estrategias deliberadas, de estrategias emergentes $y$ el ciclo entre ellas}

\subsection{La formación de estrategias deliberadas me- diante un mecanismo evolutivo de selección}

El argumento central para pensar en la formación de estrategias deliberadas mediante un mecanismo de selección, y de acuerdo con Andrade (2003), es que el proceso ontológico y epistemológico centrado en

12 Este último aspecto conduce a considerar la estrategia como un patrón, o una forma de conducta predeterminada característica en el tiempo. Cuando los patrones de comportamiento provienen de una determinada forma de concebir el papel de la organización en el entorno, la estrategia es concebida como una perspectiva, la cual orienta y da coherencia a las actuaciones de la organización en el tiempo.

13 Mintzberg señala que el término estrategia ha sido definido de múltiples formas, pero casi siempre resulta común en ellas que es un conjunto consciente y deliberado de orientaciones las cuales determinan decisiones hacia el futuro. En Mintzberg (1978) el autor muestra que en Teoría de Juegos, la estrategia representa el conjunto de reglas las cuales gobiernan los movimientos de los jugadores; mientras que en teoría militar, la estrategia está relacionada con la utilización tanto en paz como en guerra, de las disponibilidades de las fuerzas de la nación, a través de la planeación de amplia escala y largo plazo, para garantizar la seguridad y la victoria (Mintzberg, 1978 con base en Random House Dictionary)" (Montoya, 2010, 33).

14 "Mintzberg sugiere que la noción de estrategia emergente puede ser encontrada en Quinn (1980) sobre su discusión con respecto al "incrementalismo lógico", el cual caracteriza la elaboración de la estrategia tanto como un aprendizaje, así como un proceso de maniobra. Por su parte, Lindblom (1959) y Braybrooke \& Lindblom (1963) se enfocan en el rol del liderazgo formal y lo reemplazan con ajustes mutuos en retroalimentaciones entre múltiples actores.

15 Los avances en el estado de la literatura, en lo relacionado con estrategia emergente, sugieren que es un proceso incremental de prueba y error, en el que se privilegia cierta amplitud del enfoque general de la organización en cuanto a sus políticas y objetivos, o en el cual se busca ex-post una orientación generalizante de decisiones y acciones ya emprendidas, para preservar posiciones de interés bajo la administración de coaliciones internas y externas (Radich et al., 2005).

16 Es en el marco de este panorama que Radich et al. (2005) proponen la existencia de un sistema de gestión estratégica emergente, basado en el incrementalismo discontinuo de Lindblom, el incrementalismo lógico de Quinn y la estrategia emergente propiamente dicha, con aportaciones originales de Lynch. Este sistema permitiría ajustar y recoger los residuos de racionalidad no acogidos en la planeación estratégica (deliberada) y contribuirían a dar flexibilidad estratégica a la organización frente a variaciones de relevancia en el entorno" (Montoya, 2010, 41). 
una representación de comportamiento determinístico del mundo conduce a que el observador externo no necesite utilizar resultados de sus interacciones con otros entes para producir cambios funcionales en su forma de representarse, o de reconocer el mundo, por lo que sus dispositivos de medida serán invariantes, lo que posibilita la operación de un mecanismo de selección mecánico (Andrade, 2003).

En tanto un ente retroalimenta su dispositivo ontológico-epistemológico en las diversas interacciones que hace con respecto a otros entes y su entorno, lo que se observa es que dentro de su posición como observador externo, tales retroalimentaciones no generan variaciones en la forma del ente de concebir su mundo circundante. De hecho, lo que acontece es un reforzamiento de su manera particular de comprender el mundo, pues la nueva información se procesa con el mismo enfoque epistemológico y las mismas prácticas de conocimiento, y con los mismos procesos heurísticos. Incluso, los datos relevantes son únicamente aquellos que se traducen en una validación o verificación de la forma del ente de representarse el mundo, que corresponde a la de un observador externo.

Es por ello que en el proceso puede hacerse abstracción del mundo "real", pues la estrategia deliberada es un proceso de comunicación de un ente, primordialmente con su propia representación del entorno y de los otros entes. Y cualquier interacción real, va a traducirse en una verificación y diálogo del ente con su dispositivo de observador externo. Así, la decisión deliberada de interés se constituye en la que se explica por una decisión representada por un ente consigo mismo, que luego resulta en una decisión representada por el ente con otro, pues es a ésta que se reducen las demás.

El ente inicia con una configuración inicial, que es una dotación de recursos y una red de actividades que se constituyen en su proceso de producción de sí mismo. Esta configuración también incluye su forma de representarse el mundo en tanto dispone de un ciclo de producción de sí, una base de conocimiento y una idiosincrasia propia en el comportamiento, que está asociada a la configuración de su red de actividades y procesos, y al grado de interacciones de sus nichos representacionales internos.
El ente posee también las características de un agente autónomo y estará en posibilidad de realizar aprendizaje, que se relaciona con un proceso dinámico que gobierna la transformación de la información que registra y codifica un ente, en características comprensivas (cognitivas), el cual toma lugar en un espacio de representaciones donde los agentes poseen una comprensión imperfecta, mediante representaciones del mundo.

Al respecto señala Hernández (2008) que las acciones de coordinación deliberada entre individuos, con habilidades intrínsecamente diferentes y con procesos de aprendizaje distintos, generan trayectorias dentro de entes, diferentes entre sí, para obtener los datos, extraer y asimilar la información y generar conocimiento aplicable. Además Hodgson (2004) sugiere que el conocimiento adquirido por un ente afectará la selección, interpretación y entendimiento que realice, y así se conformarán las trayectorias de aprendizaje.

Una vez definido el ente y sus condiciones iniciales, el ente procura su adaptación y se vincula estrechamente con procesos de medición, registro y compresión de la información, que precisan de la selección natural (Gould, 1996), mediante una imagen inicial de sí mismo en el sistema representacional de interacciones. Sobre la base de esta interacción el agente "toma una decisión", la que conduce a un nuevo sistema de interacciones representacional, con otro ente. La decisión resultante va a ser trasladada al mundo real de interacciones, que se modelará también como uno determinístico, y tomará un papel central en la forma como el ente se representa el mundo. El observador externo, si bien interactúa con el mundo real, es un ente puramente representacional, pues hace equivaler sus interacciones "reales" con su proyección, mediante sus capacidades cognitivas, y como se mencionó, la información que escoge del mundo real, es aquella que convalida su imagen del mundo. Para filtrar las informaciones, suele exhibir una marcada coherencia hacia un polo consistente, la que hará reinterpretar todos los datos y registros en términos de su forma de percibir el mundo real. Es pertinente aclarar que el ente puede ganar en flujo de interacciones y en el número de variables que debe "manejar", pero su representación sigue siendo relativamente la misma. 
Así el ente, dentro de su población, elabora una capacidad limitada para consumir materiales y energía de otros entes, y también emplea mecanismos para registrar y procesar alguna información.

En la literatura, el mecanismo de selección implica, siguiendo a Aldrich et al. (2008), que un conjunto anterior de entes, cada uno representándose a otros, mediante un proceso determinado, se transforman en un conjunto posterior donde todos los miembros del conjunto posterior son suficientemente similares a algunos miembros del conjunto anterior, y donde las frecuencias resultantes de las entidades en el conjunto posterior dependen de propiedades de factores ambientales.

Así, a través de la selección, una población podrá gradualmente adaptarse en respuesta al criterio definido por un factor ambiental. Mientras se sostiene esto, es importante resaltar que el principio de variación requiere alguna explicación de las fuentes de variedad y "llenado". Para Aldrich et al. (2008), la evolución de instituciones sociales involucra imitación, planeación y otros mecanismos muy diversos a los detallados en biología, mientras que en cuanto a la retención se exhibirá la replicación de hábitos, reglas y rutinas, todas ellas que pueden estar orientadas a la solución de problemas de adaptación (Vanberg, 1994; Aldrich et al., 2008).

Un primer momento del funcionamiento del mecanismo de selección se da cuando en un sistema "representacional" de interacciones, el ente abre el espacio de otro a un nicho "representado". Los nichos van a superponerse como espacios de figuración y van a competir entre ellos, para buscar a un "ganador", el cual va a configurarse como una decisión en otro sistema de interacciones, y va a dar al ente una satisfacción sobre la bondad de su proceso de "planeación", entendida como la anticipación y el establecimiento de un nicho representacional que se desdobla en políticas, metas, actividades, etc.

La decisión que proviene de la estrategia deliberada debe en algún momento de su proceso entrar a un sistema "real" de interacciones, y va a fracturar en algún grado la simetría del espacio de nichos de un ente de jerarquía superior. Allí se sucede una nueva selección, la que ocurre a través de la competición entre entes y quienes resultan mejor acoplados a la red de actividades y flujos materiales del ente de jerarquía superior, lograrán una mejor viabilidad mediante un mejor ajuste para realizar un ciclo de trabajo. El rompimiento que hace esta última decisión en el sistema "real" de interacciones, tiene una importante implicación y es que el plan realizado por el ente es confrontado con la disponibilidad real del ente con el cual interactúa. Y en ese relacionamiento, los desajustes de la decisión que hagan inviable al ente, solamente podrían remediarse con una actuación rápida y local, para lograr extraer energía aprovechable para realizar un trabajo que haga viable al ente, y que requieren de un cambio dialógico en la concepción de la realidad, de forma que el ente se represente la realidad mediante un dispositivo de observador interno, y de paso a la reacción con una estrategia emergente.

Es así como el mecanismo de selección, conduce a la formación de una estrategia emergente. Sin embargo, las nuevas informaciones que resultan de la aplicación de una estrategia emergente puntual por parte de un agente, que por lo general tiene un dispositivo ontológico-epistemológico de observador externo, va a ser el de recopilar información sobre la implementación de una estrategia emergente y solamente registrar la información que va a reforzar la aplicabilidad de su forma de ver el mundo como observador externo. Así, solamente van a realizarse pequeños cambios en sus patrones recurrentes de interacción individuales y colectivos y en el tipo de reglas del tipo SI-ENTONCES del ente.

De acuerdo con Dosi, Nelson \& Winter (2000), la diferencia entre planeación deliberada, estratégica e intencional, en contraste con un desempeño de carácter cuasiautomático genera las trayectorias históricas e idiosincrásicas de cada firma.

Por último, resulta paradójico que el "éxito" de la estrategia deliberada, y su estabilidad evolutiva, se debe en buena medida a la formación y puesta en marcha de una "termodinámica" estrategia emergente. 


\subsection{La formación de estrategias emergentes, mediante un mecanismo evolutivo de observadores internos}

Para pensar en la formación de estrategias emergentes mediante un dispositivo de agentes autónomos que obran como "observadores internos".

Para Kauffman, un ente autónomo es un sistema termodinámico abierto impulsado por fuentes externas de materia y energía que mantienen al sistema fuera del equilibrio. Kauffman sugiere que estos entes enlazan procesos espontáneos y no espontáneos mediante complejas redes de interacciones que dan por resultado la reproducción y los persistentes ciclos de trabajo con los que actúan sobre una red de actividades reales. Menciona el autor que el ente autónomo molecular es un sistema dotado de dos características fundamentales de los sistemas vivos: auto-reproducción y metabolismo. Otro punto a resaltar es que este agente autónomo es necesariamente un sistema fuera de equilibrio, que ejecuta un ciclo, y que al hacerlo, alcanza una organización repetitiva del proceso, lo que le supone una ventaja selectiva respecto a un sistema auto productor de sí en comportamiento de equilibrio (Kauffman, 2003).

La principal conclusión de Kauffman, es que los agentes autónomos que acoplan ciclos de trabajo constituyen una forma totalmente plausible de redes de reacciones abiertas y fuera de equilibrio. Para entender el funcionamiento del agente autónomo es necesario reexaminar el concepto físico de trabajo en el contexto de los ciclos de trabajo, en el sentido de entenderlo como una liberación restringida de energía. Las propias restricciones a esa liberación de energía, esenciales para que el trabajo se produzca, son los equivalentes para el autor a las ruedas y bielas de una máquina ordinaria. Se requiere normalmente trabajo para construir las restricciones a la liberación de energía que hacen que el trabajo se obtenga. El entramado de actividades coherente en la construcción de conjuntos de restricciones a la liberación de energía para obtener trabajo, es a su vez empleado en la creación de nuevos condicionantes en la extracción de energía (cuyo resultado es la obtención de una copia del agente mismo) (Kauffman, 2003).
Bajo esta conceptualización, el ente, mediante la realización de medidas sobre otro, permite que la información que sea obtenida pueda ser empleada para extraer trabajo, de la misma forma como funcionan los molinos de viento. Así, lo que sucede en un ente, es que por lo general entes de jerarquía inferior, construyen y propagan conjuntamente redes y procesos de trabajo -de elaboración de restricciones y subsiguiente obtención de trabajo- que proliferan y se difunden, diversificando a su vez el entramado de redes y relaciones de actividades y procesos.

Así, los procesos de emergencia de estructuras de segundidad, suponen estar en capacidad de determinar todas las potenciales adaptaciones que podrían surgir en un ente, y preestablecer el espacio de configuraciones de éste. En tanto entes de jerarquía inferior construyen conjuntamente un ente, cada uno es capaz de clasificar y realizar actuaciones en el mismo ente, conectándose a la red de actividades del mismo, en su propio beneficio. Dentro de esta perspectiva de observadores internos, los entes coevolucionan al realizar la máxima diversidad de discriminaciones fiables sobre las que basan sus actos. Las comunidades de entes coevolucionarán hacia una "frontera del caos" y avanzarán continuamente hacia la novedad, mediante la noción de Kauffman de lo "adyacente posible", persistentemente explorado al interior de un ente de jerarquía superior, en donde se origina mayores espacios hacia la variedad. La idea de Kauffman de adyacente posible va a sugerir que entes de jerarquía superior, en promedio, puede que alcancen lo adyacente posible tan rápido como sea sostenible, pues estos entes, tienden a maximizar su dimensionalidad, el número de clases de actuaciones que pueden tener lugar a continuación (Kauffman, 2003).

Así, un ente autónomo opera con un proceso ontológico y epistemológico centrado en una representación del comportamiento complejo dela red real de actividades, y opera como un observador interno dentro de ella para lograr ventaja termodinámica.

En tanto un ente se retroalimenta en las interacciones que hace con respecto a otros entes y su entorno, lo que se observa es que en su condición de observador interno, tales retroalimentaciones producen 
pequeñas variaciones y confirman la forma del ente para ejecutar un trabajo, en su red de actividades y procesos, y en sus estructuras de segundidad. Así, se produce un reforzamiento de su manera particular de realizar un ciclo de trabajo que lo haga viable en el ente con el que interactúa.

Los ciclos pueden corresponder a la repetición en la realización de transacciones (Coase, 1937), o a la repetición en la elaboración y ejecución de determinado tipo de contrato. Un enfoque así, pone dentro de la perspectiva de los observadores internos las aportaciones sobre el problema evolutivo del oportunismo y las formas de governance en la contratación, y buena parte del discurso neoinstitucional, como explicaciones sobre la configuración de la red de actividades del ente que es un observador interno.

En tanto el ciclo se da entre las redes de actividades "reales" de los entes, una estrategia emergente básica es en realidad una actuación, de un ente con otro, en el sistema de interacción real.

El ente inicia con una configuración inicial, que es una dotación de recursos y una red de actividades que se constituyen en su proceso de producción de sí mismo. Esta configuración también incluye su forma de representarse el mundo en tanto dispone de un ciclo de producción de sí, una base de conocimiento y una idiosincrasia propia en el comportamiento, que está asociada a la configuración de su red de actividades y procesos, y al grado de interacciones de sus nichos representacionales internos. El ente posee también las características de un agente autónomo y estará en posibilidad de realizar aprendizaje, que se relaciona con un proceso dinámico que gobierna la transformación de la información que registra y codifica un ente, en características comprensivas (cognitivas), que van a tomar lugar en la red de actividades y procesos del agente, y en su estructura de segundidad.

El ente procura su adaptación dentro de los nichos reales de otro ente, a la manera de un observador interno. En esta interacción "real", el ente "realiza una actuación", que afecta su proceso de producción de sí, en tanto lo habilita de manera novedosa para extraer energía, recursos e información del ente.
La naturaleza de estas interacciones es tal que los paisajes de estructuración se bifurcan en tanto los entes realizan actuaciones que fracturan la simetría al interior del ente con el que se relacionan. Cualquier actuación abre posibilidades asociadas, casi siempre en la forma de un complejo árbol de decisiones. Dentro del tal árbol, cualquier senda puede ser rastreada a un sendero anterior pero no puede ser predeterminado por este. De acuerdo con Garud \& Van De Ven (2002), puede ser posible rastrear elecciones existentes a elecciones anteriores, pero no es posible predecir elecciones futuras, basándose en elecciones presentes. Esto es porque los estados futuros están basados sobre posibilidades las cuales tendrán todavía que ser realizadas, basadas sobre elecciones pendientes de ser ejercitadas. Más importante, estas posibilidades futuras son promulgadas en cualquier punto de tiempo de manera autocomplaciente en tanto los recursos sean desplegados para aprovechar una iniciativa. En otras palabras, es posible trazar un patrón, pero no predecir el sendero exacto.

Una actuación se convierte en una perturbación en un ente cuyo tejido exhibe comportamiento biotemporal, es decir, alude a procesos auto- organizativos, y surge en tanto existe un cambio radical en la evolución de su red de interacciones. El proceso auto- organizativo en cuanto a la comprensión de las actuaciones de la estrategia emergente, se sucede cuando alguna actuación se convierte en una perturbación, la cual puede generar un proceso de conducción o que origine un rompimiento de un límite del sistema. La superación de tal punto crítico produce nuevas redes de actividades y procesos en los cuales se organiza la materia, y dispone a los entes a operar en procesos coevolutivos, de forma que se generan patrones no aleatorios, que se manifiestan en forma de olas propagatorias. Por su parte, si el proceso de la actuación - perturbación es acelerado, se posibilita la transformación de la estructura de actividades y una reconfiguración del proceso que posibilita el ciclo de trabajo termodinámico.

La actuación que proviene de la estrategia emergente, va a tomar ventaja de las oportunidades que se le ofrezcan en la estructura de nichos reales del ente, va a "corregir" la operación de la estrategia deliberada y va a fracturar en algún grado la simetría del espa- 
cio de nichos reales de un ente de jerarquía superior. Así, la estrategia emergente produce "emergencias organizacionales" o novedades en la estructuración de las redes de actividades del ente de jerarquía superior en el que se sucede la actuación, y va a modificar, incluso radicalmente, las estructuras de segundidad del ente que actúa, lo que configura todo un horizonte de posibilidades para la generación de variedad en el ente. Estas afectaciones que hace la estrategia emergente, van a producir innovaciones, a través de las modificaciones en la red de producción de sí y la manera como fluyen los recursos y la energía en el ente - y su intercambio con el ente con el que se relaciona- en el dispositivo ontológico- epistemológico del mismo ente, pues éste último va a representarse el mundo "real" de maneras novedosas por cambios en sus hábitos o rutinas, en su cultura y su producción misma. También van a producirse cambios debido a que el espacio de nichos reales va a verse afectado y se da una redefinición conceptual del ente a ser representado, por las innovaciones surgidas en sus estructuras de segundidad.

Así, la estrategia emergente juega un papel dramático en la generación de variedad de los entes, en la configuración de las estructuras de segundidad del ente, y afecta la "formulación" de estrategias deliberadas en tanto afecta la percepción ontológica - epistemológica del ente.

Por estas conexiones, resulta explicable que el "éxito" de una estrategia emergente, se deba en buena medida a la "preparación del terreno" para su ejecución, lo que implica la toma de decisiones y actuaciones con estrategias deliberadas que van a afectar incrementalmente condiciones en los entes con los que se suceden interacciones, y que posibilitan el camino a una perturbación que pueda redefinir las formas de competición y la viabilidad de los procesos productivos de sí mismos de los competidores. Las teorías del cambio organizacional aluden a porciones de este proceso, que resulta mejor explicado en el marco de la generación de estrategias deliberadas, por parte de estrategias emergentes, y su ciclo.

\subsection{El ciclo entre estrategias deliberadas y emer- gentes}

La idea de ciclo proviene de la conexión de las dos secciones anteriores, que sucede en el dispositivo cognitivo del ente. Así, y parafraseando a Andrade (2003), la relación de un ente con otro y las adaptaciones en su proceso evolutivo aluden a varios niveles:

I. Un ente como agente autónomo procura su viabilidad, y en tanto posee de un dispositivo cognitivo, puede exhibir intencionalidad;

II. los entes orientan sus propias condiciones de evolución y selección a través de la modificación permanente de su entorno, de acuerdo con su intencionalidad;

III. los entes son también entes (entornos) de otros;

IV. por ello, los entes generan constantemente decisiones y actuaciones. Las actuaciones resultan en desafíos que deben enfrentar los otros entes, por lo que el orden se traduce en tendencias al desorden;

V. la actuación del ente que hace de entorno, induce modificaciones, puede dar lugar a variaciones;

VI. la operación del ente que hace de entorno sobre otros entes, a nivel de la población, origina presiones de selección impuestas por las condiciones externas;

VII. cuando hay desadaptaciones en tanto se dan las presiones de selección y hay dinámicas en la acomodación de nichos, el ente que opere como entorno, el cual está lleno de un potencial generativo muy grande y que facilita diversos flujos de energía y de materiales, hace posible procesos de auto-organización y ciclos de trabajo termodinámicos, que afectan la producción de sí de un ente y cuya percepción del mundo opera en el marco de observadores internos. Se trata de la emergencia del orden a partir del caos; 
VIII. el dispositivo cognitivo se ve afectado por los cambios en la red de actividades que producen el ciclo de trabajo del ente y por la aparición de novedades en el entorno. Esta influencia origina una nueva representación de la realidad;

IX. el ciclo se cierra al comenzar una reorientación de la intencionalidad.

Los entes que participan en flujos cíclicos se favorecen de la retención de recursos y energía. Los recursos retenidos pueden ser explotados más adelante, ya que ofrecen la posibilidad de nuevos nichos, tanto representacionales como reales. Según Holland (2004), la selección natural debe ser entendida en términos de un proceso cíclico que conduce al incremento de la diversidad a través del acrecentamiento del reciclaje.

Esta noción, finalmente, es la que va a representar la ventaja para un ente, que se hará viable en cuanto a su aumento de reciclaje, tanto en recursos como en bloques de construcción y estructuras de las prácticas de conocimiento para representarse o actuar con otros entes.

También le dará ventaja la "administración" de la ejecución del ciclo de entes con estrategias deliberadas y emergentes. El ciclo mismo es un proceso auto- organizativo, que genera acumulaciones de bucles en el mismo circuito, que perturban su estructura y hacen avanzar el sistema completo hacia novedades no configuradas previamente.

El ciclo plantea una representación sobre cómo se genera variedad en procesos evolutivos y hace una propuesta novedosa sobre la manera de establecer intencionalidad en procesos que configuran patrones.

Del mismo modo resulta posible plantear a partir de la enunciación del ciclo de entes con estrategias deliberadas y emergentes, una herramienta para medir los cambios en cognición de un ente, la cual tendrá diferentes "momentos", en tanto se recorre una vuelta completa en el ciclo. Así se puede comparar la acumulación de experiencia propia e idiosincrática de cada ente, consigo mismo, luego de darse una vuelta en tal circuito.
De igual manera se proponen alternativas para la "medición" de la estrategia, la cual puede hacerse en el establecimiento de una declaración estática de un ente, cuando se prepara para la decisión con relación a un nicho en otro ente. Puede "medirse" posteriormente, una vez el ente haya realizado el ciclo descrito, en el mismo punto, y apreciar las variaciones, seguramente sutiles, que provienen del recorrido por las instancias del proceso descrito.

Quizás la mejor metáfora para comprender el ciclo de estrategias deliberadas y emergentes, con sus posibilidades de retroalimentaciones internas y sus contingencias, que provienen de la decisión y actuación simultánea de otros entes, así como del emprendimiento por parte de un ente de múltiples ciclos simultáneos, es pensar en el circuito como un proceso de "respiración" cognitiva, en el cual el ente expira e inspira, y ese proceder transforma su red de actividades y componentes para mantener la adecuación y viabilidad dentro de un nicho del mundo real.

\subsection{La "consciencia" de los entes}

Kauffman (2003) explora posibilidades de los agentes autónomos y su ocasión de constituirse en entes con cierto dispositivo de consciencia. Tal eventualidad se explora a continuación, con apego a la orientación del autor.

En la realización del ciclo enunciado, es prudente decir que puede explorarse la posibilidad de interacciones entre decisiones y actuaciones. Ambas resultan, en tanto producto de procesos, en reducciones dimensionales y "condensaciones" de un nivel dimensional superior en cuanto número de variables. Alguna discordancia puede aparecer entre la interacción de dos decisiones de entes diferentes, o de la decisión de un ente con relación a la decisión de otro ente que obra como entorno y que se encuentran de manera simultánea. También puede darse tal discordancia entre interacciones de decisiones con actuaciones. Estas interacciones van a originar discordancias en la decisión, y las actuaciones van a "desintegrar" la decisión y la van a llevar al mundo de los nichos reales.

Esta desintegración de la decisión, cuando interactúa en simultánea con una actuación de otro agente, 
y que la hace pasar del mundo de las representaciones al mundo real, deja a los entes que se relacionan en un estado real de las interacciones de sus redes de actividades, en una situación concreta.

Cada estado "concreto" va a generar restricciones en el mundo real, que van a orientar futuras "desintegraciones representacionales" de las decisiones, en el marco de tales limitaciones. La persistencia de decisiones en el sistema representacional de interacciones, y la eventual "desintegración representacional", se puede comprender como un mecanismo de consciencia, así como la experimenta el ente autónomo.

La continuidad de tal consciencia dependería de un equilibrio dinámico que permita que la formación de decisiones intencionadas se renueve sistemáticamente a lo largo del ciclo, al menos con la misma velocidad que ocurren las desintegraciones representacionales.

\section{Conclusiones}

La relevancia de la estrategia en la comprensión de procesos evolutivos cada vez ocupa un lugar más preponderante, no solo porque ofrece una explicación sobre la generación de procesos de variación en la evolución de las organizaciones y sus rutinas, sino porque además permitiría eventualmente explorar una alternativa de explicación sobre cómo pueden microfundarse las rutinas organizacionales en las capacidades de los agentes que componen estas organizaciones. Adicionalmente, la estrategia se configura como orientadora de la acción de entes y tales acciones resultan ser emprendidas declaraciones del mundo, fundadas sobre una percepción del mundo y la construcción de respuestas típicas a problemas genéricos.

En la propuesta que se presenta, la percepción del mundo que asumen los entes, sobre la cual realizan acciones (y dentro de las acciones realizan prácticas de conocimiento), que incorporan a sus dispositivos de retención y que proyectan para interpretar nichos reales y sus posibilidades, se elabora a través del ejercicio del relacionamiento en los sistemas representacional y real de interacciones.

La reconstrucción de los conceptos mencionados mediante la metodología de sistemas suaves permite contribuir a volver operacionalizable para el investigador el proceso de formación de la estrategia y a establecer conexiones entre el mundo que se representa el estratega para anticipar sus compromisos a la acción, y los eventos que suceden en el "mundo real". El documento explora la problemática de la formación de la estrategia desde un enfoque evolutivo y bajo la suposición de un ciclo entre estrategias deliberadas y emergentes (Montoya, 2010), para lo cual, realiza una revisión de sus concepciones mediante la metodología de sistemas suaves. Para su desarrollo propuso la interacción de entes, los cuales fueron definidos como agentes, organizaciones y entorno, y reconstruye el concepto de estrategia.

Trabajos futuros en el campo de la formación de la estrategia pueden surgir a partir de las reflexiones propuestas, en particular sobre la manera como se interconectan la "realidad" y el mundo "representacional" en el actuar del estratega o de la organización que se desempeña estratégicamente, tanto en el campo teórico como empírico. El enriquecimiento de las ciencias económicas con la indagación sobre los procesos psicológicos, cognitivos y de comportamiento, viene consolidándose como un espacio promisorio en el desarrollo de las disciplinas que las componen, por lo que novedosas interacciones entre estos campos pueden derivar nuevos productos académicos para profundizar en el proceso de formación de la estrategia.

\section{Referencias}

Aldrich, H., Hodgson, G., Hull, D., Knudsen, T., Mokyr, J. \& Vanberg, V. (2008) In defense of generalized darwinism. En: Journal of evolutionary economics. Springer Ed. Vol.18 No. 5: 577-596.

Aldrich, H. \& Ruef, M. (2006) Organizations evolving. London: Sage. Andrade, L.E. 2003. Los demonios de Darwin. semiótica y termodinámica de la evolución biológica. $2^{\mathrm{a}}$ Ed. Universidad Nacional de Colombia, Facultad de Ciencias, Departamento de Biología, 265p.

Bennett, Charles H. (1987) "Demons, Engines and the Second Law”. En: Scientific American:108-116 (November, 1987).

Bleda, M. (2001) Evolutionary economics and complex systems theory. Thesis submitted to the University of Manchester for the degree of Phd in Economics in the Faculty of Social Science and Law.

Braybrooke, D., \& Lindblom (1963) A strategy of decision. Free Press, New York.

Chakravarthy, B., Roderick, Y. \& White, E. (2002) Strategy process: forming, implementing and changing strategies. En: Pettigrew, 


\section{LA FORMACIÓN DE ESTRATEGIAS DELIBERADAS Y EMERGENTES: UNA PROPUESTA A PARTIR DE DEFINICIONES BÁSICAS DE UNA METODOLOGÍA DE SISTEMAS SUAVES}

Andrew, T. Howard \& R. Whittington (2002) Handbook of Management \& Strategy. Sage Publications. London. 519p.

Checkland, P., \& Scholes, J. (1994) La metodología de sistemas suaves en acción. Colección Megabyte. Ed. Noriega. México.

Coase, R. (1937) "The Nature of the Firm". Economica (Blackwell Publishing) 4 (16): 386-405. doi:10.1111/j.1468-0335.1937. tb00002.x. JSTOR 2626876.

Cyert, R. \& March, J. (1963) A behavioral theory of the firm. Englewood cliffs, Prentice-Hall. N. J.

Dosi G., Nelson R. \& Winter S. (2000) The nature and dynamics of organizational capabilities. Oxford university press. Gb.

Eisenhardt, K. \& Martin, J. (2000) Dynamic capabilities: what are they? En: Strategic Management Journal, 21:1105-1121.

Fraser; J. (1975) Of Time, Passion and Knowledge: Reflections on The Strategy of Existence. New York: George Braziller, Inc., 52p.

Garud, R. \& Van, de Ven (2002) Strategic Change Processes. En: Pettigrew, A.M., H. Thomas, y R. Whittington (Eds). Handbook of Strategy and Management. Sage Eds, London: 206-231.

Gindis, D. (2007) The Firm as an Entity: Implications for Economics, Accounting and Law. Biondi, Y., Canziani , A. \& Kirat, T. (eds.). London: Routledge: 266-291.

Gould, S. (1996) Creando a los creadores. En: Antracnosis. Traducción de Enrique Torres, profesor Emérito, Universidad Nacional de Colombia.

Guyot; V. (2005) Conceptos Extranjeros, Campos de Conocimiento y Complejidad. En: Educación y Alteridad. Ediciones Novedades Educativa.

Hatten, K. (1999) Managing the Process-Centered Enterprise. En: Long Range Planning, London, Vol. 32, Iss. 3.

Hernández, I. (2008) Empresa, innovación y desarrollo. Bogotá, Universidad Nacional de Colombia y Unibiblos.

Hodgson, G. (2004) The evolution of institucional economics. New York, Routledge, 2004.

Hodgson, G. (1994) The return of institutional economics. In: Smelser N.J. and R. Swedberg (eds.). En: The handbook of economic sociology: 58-76. Princeton, NJ: Princeton University Press.

Holland, J.H. (2004) El orden oculto, de cómo la adaptación crea la complejidad. Fondo de Cultura Económica, México. 193p.

Kauffman, S. (1993) The origins of order: self-organization and selection in evolution. Oxford University Press, New York.

Kauffman, S. (2003) Investigaciones. Metatemas, España.

Lewin, A. \& Volberda, H. (1999) Prolegomena on convolution: a framework for research on strategy and new organizational forums. En: Organization Science, 10(5): 519-534.

Lindblom, C. (1959) The science of 'muddling through'. En: Public Administration Review, Vol. 19: 79-88.

March, J., \& Simon, H. (1958) Organizations. Wiley \& Sons.

Metcalfe, J. (1997) Labour markets and competition as an evolutionary process. En: Arestis, P., G. Palma and M. Sawyer (eds). Markets, employment and economic policy: essays in honour of Geoff Hartcourt. London: Routledge: 328-43.

Mintzberg, H. (1978) Patterns in strategy formation. En: Management Science, XXIV(9): 934-948.
Mintzberg, H. (1987) The strategy concept i: five ps for strategy. Fall 1987, California Management Review.

Montoya, I. (2010) Una contribución a la comprensión de las estrategias deliberadas y emergentes de las organizaciones, desde una perspectiva evolutiva. Doctorado thesis, Universidad Nacional de Colombia. Disponible en: http://www.bdigital. unal.edu.co/2141/

Montoya, I. (1999) Gestión Global, Siglo XXI, Universidad Nacional de Colombia, Bogotá

Montoya, A. \& Montoya, I. (2003) el direccionamiento estratégico y su aplicación en los sistemas complejos y en la gerencia ambiental. En: Revista Innovar, No. 21: 81-104.

Montoya, I. \& Leon, E. (2004) los ciclos de generación de competencias y su aplicación en las organizaciones. En: Revista Innovar, Julio - Diciembre de 2004, No. 24: 9-27.

Nelson, R. \& Winter, S. (1982) An evolutionary theory of economic change. Cambridge Ma: Belknap Press.

Nicolis, G. \& Prigogine, I. (1989) Exploring Complexity: An Introduction. Piper, Munchen.

Peirce, C. (1965) Collected papers. Harvard University Press, Cambridge, M.A.

Popper, K. (1986) El universo abierto. un argumento a favor del indeterminismo. Tecnos Ed. Madrid.

Quinn, J. (1980) Strategies for change: logical incrementalism. Irwin, Homewood, Ill.

Radich, F., Drejer, A. \& Printz, L. (2005) Emergent strategisk ledelse - vejen frem...? Beskrivelse og analyse af emergent strategisk ledelse som teoretisk ledelsesbegreb og praktisk ledelsesværktøj. Strategy_Lab®, V/Institut for Ledelse, Handelshøjskolen I Århus. 74p.

Simon, H. (1945) Planning for organization and management. En: Public Management, 27, 108-111.

Stacey, R. (1991) The chaos frontier. Creative strategic control for business. Butterworth-Heinemann. Redwood Press, Wiltshire, GB. 409p.

Schwartz; B. (1976) Review of Time, Passion And Knowledge: Reflections on The Strategy of Existence. En: The American Journal of Sociology, Vol. 82 No.1, P. 265-267.

Teece, D.J. (1988) Technological change and the nature of the firm. In: Dosi, G. (Ed.). Technical change and economic theory. London, Pinter Publisher.

Teece, D.J., Pisano, G. \& Schuen, A. (1997) Dynamic capabilities and strategic management. En: Strategic Management Journal, 18(7), 509-530.

Teece, D., Rumelt, R., Dosi, G., \& Winter, S. (1994) Understanding corporate coherence. En: Journal of Economic Behavior and Organization, 23: 1-30.

Vanberg, V. (1994) Rules and choice in economics. Londres, Routledge.

Zurek, W. (1989) Algorithmic randomness and physical entropy. En: Physical Review, 40 (8): 4731-4751. 